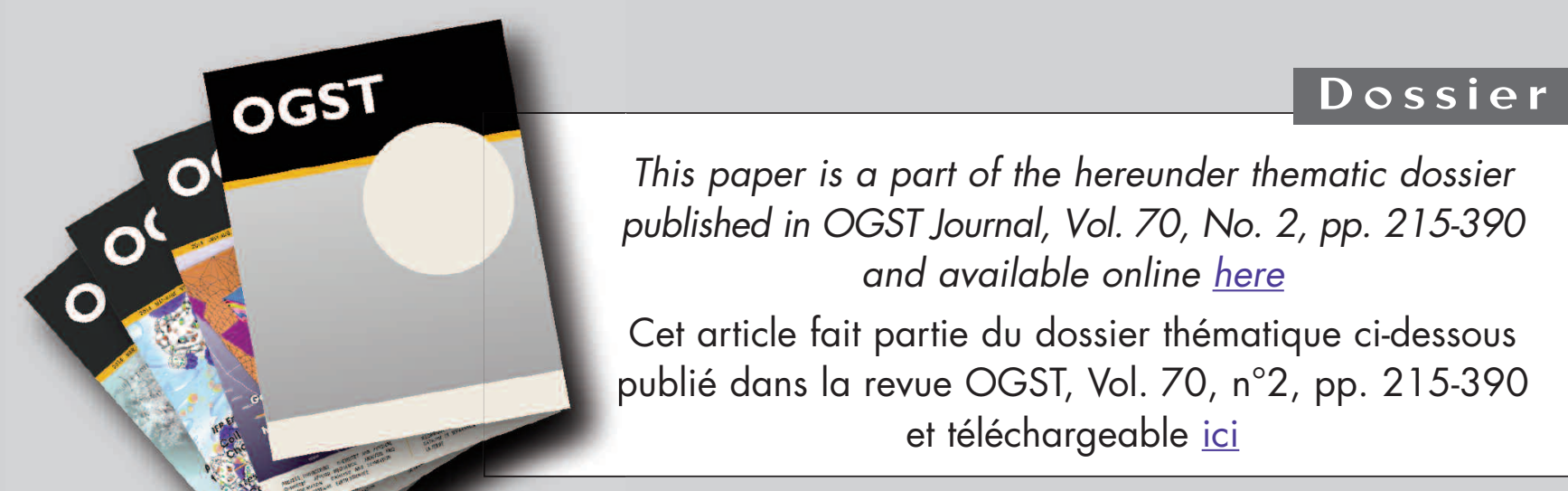

DOSSIER Edited by/Sous la direction de : B. Dewimille

Fluids-Polymers Interactions: Permeability, Durability

Interactions fluides polymères : perméabilité, durabilité

Oil \& Gas Science and Technology - Rev. IFP Energies nouvelles, Vol. 70 (2015), No. 2, pp. 215-390

Copyright (C) 2015, IFP Energies nouvelles

$215>$ Tribute to Yves Chauvin Hommage à Yves Chauvin

S. Candel and 0 . Appert

$219>$ Editorial

G. Kimmerlin

227 > Gas Permeation in Semicrystalline Polyethylene as Studied by Molecular Simulation and Elastic Model

Perméation de gaz dans le polyéthylène semi-cristallin par simulation moléculaire et modèle élastique

P. Memari, V. Lachet and B. Rousseau

237 > Reinforcement of the Gas Barrier Properties of Polyethylene and Polyamide Through the Nanocomposite Approach: Key Factors and Limitations

Renforcement des propriétés barrière aux gaz de matrices polyéthylène et polyamide par l'approche nanocomposite : facteurs clés et limitations E. Picard, J.-F. Gérard and É. Espuche

251 > Diffuso-Kinetics and Diffuso-Mechanics of Carbon Dioxide / Polyvinylidene Fluoride System under Explosive Gas Decompression: Identification of Key Diffuso-Elastic Couplings by Numerical and Experimental Confrontation

Cinétique de diffusion et comportement diffuso-mécanique du système dioxide de carbone / polyfluorure de vinylidène sous décompression explosive de gaz : identification des couplages diffuso-élastiques majeurs par confrontation numérique et expérimentale

J.-C. Grandidier, C. Baudet, S. A. E. Boyer, M.-H. Klopffer and L. Cangémi

267 > Characterization of Polymer Layered Silicate Nanocomposites by Rheology and Permeability Methods: Impact of the Interface Quality

Caractérisation de nanocomposites polymère silicate par des méthodes de rhéologie et de perméabilité : rôle de la qualité de l'interface

R. Waché, M.-H. Klopffer and S. Gonzalez

$279>$ Evaluation of Long Term Behaviour of Polymers for Offshore Oil and Gas Applications

Durabilité des polymères pour application pétrolière offshore

P.-Y. Le Gac, P. Davies and D. Choqueuse

$291>$ Development of Reactive Barrier Polymers against Corrosion for the Oil and Gas Industry: From Formulation to Qualification through the Development of Predictive Multiphysics Modeling

Développement de matériaux barrières réactifs contre la corrosion pour l'industrie pétrolière : de la formulation à la qualification industrielle en passant par le développement de modèles multiphysiques prédictifs

X. Lefebvre, D. Pasquier, S. Gonzalez, T. Epsztein, M. Chirat and F. Demanze
$305>$ Development of Innovating Materials for Distributing Mixtures of Hydrogen and Natural Gas. Study of the Barrier Properties and Durability of Polymer Pipes

Développement de nouveaux matériaux pour la distribution de mélanges de gaz naturel et d'hydrogène. Étude des propriétés barrière et de la durabilité de tubes polymères

M.-H. Klopffer, P. Berne and É. Espuche

317 > New Insights in Polymer-Biofuels Interaction

Avancées dans la compréhension des interactions polymères-biocarburants E. Richaud, F. Diouani, B. Fayolle, J. Verdu and B. Flaconneche

$335>$ Biofuels Barrier Properties of Polyamide 6 and High Density Polyethylene Propriétés barrière aux bio essences du polyamide 6 (PA6) et du polyéthylène haute densité (PEHD)

L.-A. Fillot, S. Ghiringhelli, C. Prebet and S. Rossi

353 > Permeability of EVOH Barrier Material used in Automotive Applications: Metrology Development for Model Fuel Mixtures

Perméabilité d'un matériau barrière EVOH utilisé dans des applications automobiles : développement métrologique pour des mélanges modèles de carburants

J. Zhao, C. Kanaan, R. Clément, B. Brulé, H. Lenda and A. Jonquières

367 > Effects of Thermal Treatment and Physical Aging on the Gas Transport Properties in Matrimid ${ }^{\circledR}$

Les effets du traitement thermique et du vieillissement physique sur les caractéristiques du transport au gaz dans le Matrimid ${ }^{\circledR}$

L. Ansaloni, M. Minelli, M. Giacinti Baschetti and G. C. Sarti

381 > Separation of Binary Mixtures of Propylene and Propane by Facilitated Transport through Silver Incorporated Poly(Ether-Block-Amide) Membranes Séparation de mélanges binaires de propylène et de propane par transport au travers des membranes de poly(éther-blocamide) incorporant de l'argent R. Surya Murali, K. Yamuna Rani, T. Sankarshana, A. F. Ismail and S. Sridhar 


\title{
New Insights in Polymer-Biofuels Interaction
}

\author{
Emmanuel Richaud ${ }^{1 *}$, Fatma Djouani ${ }^{1}$, Bruno Fayolle ${ }^{1}$, Jacques Verdu' and Bruno Flaconneche ${ }^{2}$ \\ ${ }^{1}$ Arts et Métiers ParisTech, CNRS, PIMM UMR 8006, 151 bd de l'Hôpital, 75013 Paris - France \\ 2 IFP Energies nouvelles, 1-4 avenue de Bois-Préau, 92852 Rueil-Malmaison - France \\ e-mail: emmanuel.richaud@ensam.eu \\ * Corresponding author
}

\begin{abstract}
Résumé - Avancées dans la compréhension des interactions polymères-biocarburants - Cet article traite des interactions polymères-biocarburants et en particulier des effets des biocarburants sur le polyéthylène (PE) employé pour des applications automobiles. L'objectif est de développer un modèle prédictif pour la durée de vie des réservoirs en polyéthylène vieillissant au contact de carburants contenant de l'éthanol ou du biodiesel. La principale conséquence d'un vieillissement au contact d'éthanol est la diminution de la vitesse d'extraction des antioxydants $\mathrm{du}$ PE. La vitesse d'extraction obéit à une loi du premier ordre et sa constante de vitesse obéit à la loi d'Arrhenius. L'interaction entre le PE et les biodiesels a été étudiée au travers de systèmes réels (méthyl ester de soja et de colza) comparés à deux systèmes modèles (méthyl oléate et méthyl linoléate). Il en est principalement ressorti que l'interaction entre biodiesel et polyéthylène se décomposait en deux parties : une première liée au vieillissement physique dû à la pénétration du biodiesel dans le PE et l'autre à un vieillissement chimique au cours duquel polyéthylène et biodiesel s'oxydaient simultanément. L'étude du transport des méthyl esters dans le PE a révélé que la cinétique de diffusion ne dépendait que de la température et de la masse molaire du carburant. L'étude de l'interaction chimique a mis en évidence que les méthyl esters s'oxydent plus rapidement que le PE et contribuent à accélérer son oxydation. Un premier modèle de co-oxydation a été proposé pour rendre compte de ce phénomène.
\end{abstract}

\begin{abstract}
New Insights in Polymer-Biofuels Interaction - This paper deals with polymer-fuel interaction focusing on specific effects of biofuels on polyethylene (PE) in automotive applications. The practical objective is to develop a predictable approach for durability of polyethylene tanks in contact of ethanol based or biofuel based fuels. In the case of ethanol, the main consequence on $P E$ durability is a reduction of the rate of stabilizer extraction; this latter phenomenon can be modeled by first order kinetics with a rate constant that obeys the Arrhenius equation. Concerning biodiesels, the study was focused on soy and rapeseed methyl ester which were compared to methyl oleate and methyl linoleate used as model compounds. Here, PE-fuel interactions can be described as well as physical interaction, linked to the oil penetration into the polymer, as chemical interaction linked to an eventual co-oxidation of PE and oil. Both aspects were investigated. Concerning biofuel transport in PE, it appeared that the oil diffusivity depends only of temperature and oil molar mass. Some aspects of the temperature dependence of the oil solubility in PE are discussed. About chemical interaction between oil and $P E$, it was put in evidence that unsaturated fatty esters promote and accelerate PE oxidation. A co-oxidation kinetic model was proposed to describe this process.
\end{abstract}




\section{INTRODUCTION}

\subsection{Strategy}

Fuels from vegetable sources did not constitute a novelty at the beginning of the 21th century, since alcohol from sugar-cane was widely used in Brazil more than 30 years ago. What is new is the trend to generalize worldwide their use and to diversify fuel types (oils for Diesel engines based on fatty esters coexist now with ethanol) as well as vegetable sources, depending on the country of production. Automotive designers and manufacturers have to face many problems linked to the use of these fuels. We will focus here on the problems linked to eventual interactions between these biofuels (fatty acids methyl esters and ethanol) and polymer components (tanks, pipes, joints and other parts) in contact with them. Although leaching effects cannot be totally excluded, it will be considered here that most of the possible interactions result from the fuel penetration in the polymer. They are schematized in Figure 1.

Since fuel penetration in the polymer is the first step of any ageing process, its analysis must be the first step of any quantitative study of such processes. Two key characteristics determine the behavior of the polymer-fuel system in this domain: the fuel solubility $S$ and diffusivity $D$ in the polymer. These quantities are generally determined from sorption or permeation experiments. Generally, when the solubility is low, fuel penetration doesn't affect significantly polymer properties. It will be considered that a case of high solubility would result from a non-adequate polymer choice; this case will not be examined here.

Behind their apparent simplicity, these phenomena hide some difficulties linked for instance:

- to the fact that fuels from vegetable sources are not pure compounds, they are more or less complex mixtures;

- to the fact that the physical properties of their elementary components are not always well known. An important part of the research will thus consist to choose pure compounds representative of the industrial mixtures (and to demonstrate the validity of this choice) and to use all the theoretical resources of molecular physics to determine the physical properties not reported in literature.

Polymer ageing processes can be divided in two main categories: physical ageing in which there are no chemical modifications of macromolecules, and chemical ageing in which there are changes of the macromolecular structure and thus of physical properties which depend of this structure.

Physical ageing processes can be ranged in two categories:

- processes of polymer plasticization leading to a premature fracture under stress: static stress cracking or fatigue;

- processes of stabilizer extraction by the fuel leading to an acceleration of chemical ageing.

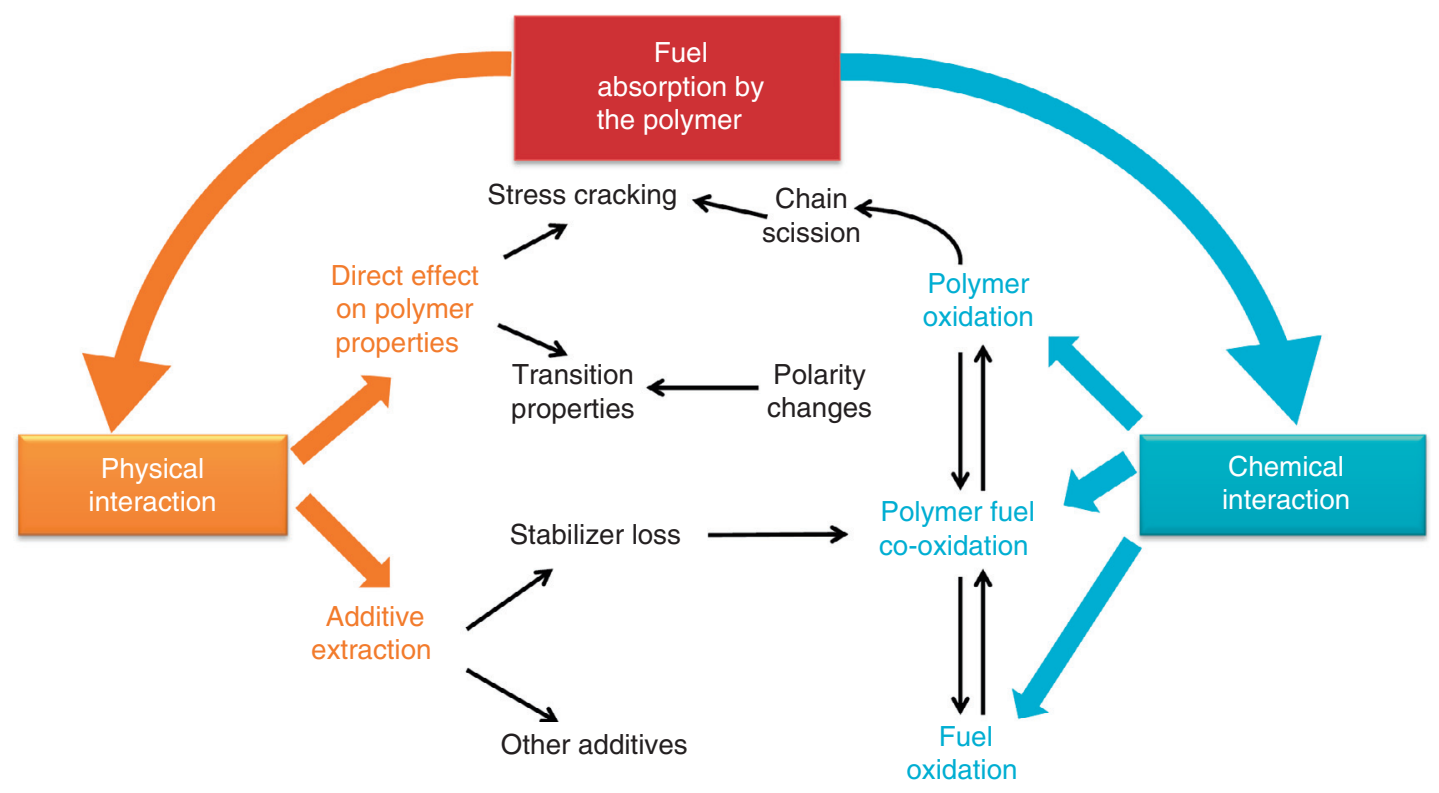

Figure 1

Schematization of possible polymer-fuel interactions having eventual consequences on polymer durability. 
Chemical processes are essentially oxidation ones in the automotive conditions where the materials are exposed to temperatures generally lower than $150^{\circ} \mathrm{C}$, in relatively dry atmospheres. The main question here is: do biofuels accelerate the polymer oxidation?

One sees many possible interactions between physical and chemical processes: indeed, extraction of stabilizers is expected to accelerate oxidative ageing. Among the consequences of this latter, two are especially important:

- the polymer resistance to stress cracking is sharply linked to its molar mass. Since oxidation induces chain scission, it is expected to decrease the polymer resistance to stress cracking;

- when the polymer is initially almost apolar (case of polyolefins), oxidation increases polarity, that can change the polymer-fuel interaction parameter(s) and have eventual consequences on polymer permeability.

The aim of this article is to illustrate the possibilities of kinetic modeling for the study of oxidation effects by an application to results obtained on some model systems. All the experimental results presented here were published elsewhere [1-4].

\subsection{Diffusion Controlled Steps of Chemical Ageing}

In a first approach, it will be considered that three molecular species, are able to be exchanged between atmosphere and the material: oil, oxygen (ox) and stabilizer (stab). Here, reactions between oil and polymer are not considered, only the physical role of oil is taken into account. The polymer-oil mixture is considered to react as a single substrate towards oxidation. There are thus two reactive species: oxygen and stabilizer (a single stabilizer is considered for the sake of simplicity) characterized by their equilibrium concentration $C_{o x}$ and $C_{\text {stab }}$ and by their diffusivity $D_{o x}$ and $D_{\text {stab }}$. These quantities can, indeed, vary with the degree of oxidation. The chemical analysis must lead to a mechanistic scheme containing all the important elementary steps among which those involving directly oxygen and stabilizer. The kinetic scheme derived from this mechanistic scheme must contain one equation per reactive species, i.e. typically 6 or 7 equations for a case of "homo-oxidation", among which the two ones relative to oxygen and stabilizer of which the specificity is to contain diffusion terms, in order to take into account the atmosphere $\leftrightarrow$ material exchanges. Their simplest expression would be:

$$
\frac{\partial\left[O_{2}\right]}{\partial t}=D_{o x} \frac{\partial^{2}\left[O_{2}\right]}{\partial z^{2}}-r_{o x}
$$

and

$$
\frac{\partial[s t a b]}{\partial t}=-D_{s t a b} \frac{\partial^{2}[s t a b]}{\partial z^{2}}-r_{s t a b}
$$

where $z$ is the layer depth in the sample thickness, $r_{o x}$ is the rate of oxygen consumption and $r_{\text {stab }}$ the rate of stabilizer consumption, both expressed in function of reactive species concentrations, $D_{o x}$ and $D_{\text {stab }}$ the respective diffusivity for oxygen and stabilizer. The boundary conditions are the oxygen equilibrium concentration and the initial stabilizer concentration.

The first step of the research, here, would consist to write the full expressions of $r_{o x}$ and $r_{s t a b}$. Then, we will face two problems linked to the fact that neither diffusivities $D_{o x}$ and $D_{\text {stab }}$ nor initial conditions are constant. The first reason is linked to the oil penetration in the polymer. Oil plasticizes the polymer, increases its segmental mobility, which presumably increases the diffusivity of small molecules. From this point of view, two situations can be found:

- if the characteristic time of oil diffusion is considerably shorter than oxidation induction time and characteristic time of stabilizer diffusion, then one can consider that the oxidation process occurs when the polymer is saturated by oil, $D_{o x}$ and $D_{\text {stab }}$ are the diffusivity values for the plasticized polymer, they are independent of oil transport parameters;

- if, in contrast, oil diffusion, polymer oxidation and thus stabilizer consumption occur in the same timescale, the above equations have to be coupled with oil diffusion one, which is a more complex situation.

From the experimental point of view, one can remark that both above equations are to be solved in time $(t)$ and in space $(z)$. The knowledge of depth distributions of stabilizer and oxidation products concentrations in sample thickness is especially interesting. The kinetic models are complex and cannot be validated only by results relative to global (average) concentrations. Experimental determinations of thickness reaction profiles will bring very useful complementary information.

\subsection{From Oxidation to Physical Properties}

If oxidation induces changes of mechanical properties, this is through molecular weight changes. In the context of oxidation of saturated hydrocarbon polymers, such changes result essentially from random chain scissions. The first step in a study of chain scission kinetics consists to determine the elementary step(s) of the mechanistic scheme in which chains are broken. The most common precursor of chain scission in radical oxidation is a secondary or tertiary alkoxy radical $\left(\mathrm{PO}^{\circ}\right)$ able to rearrange by beta scission (Fig. 2). 


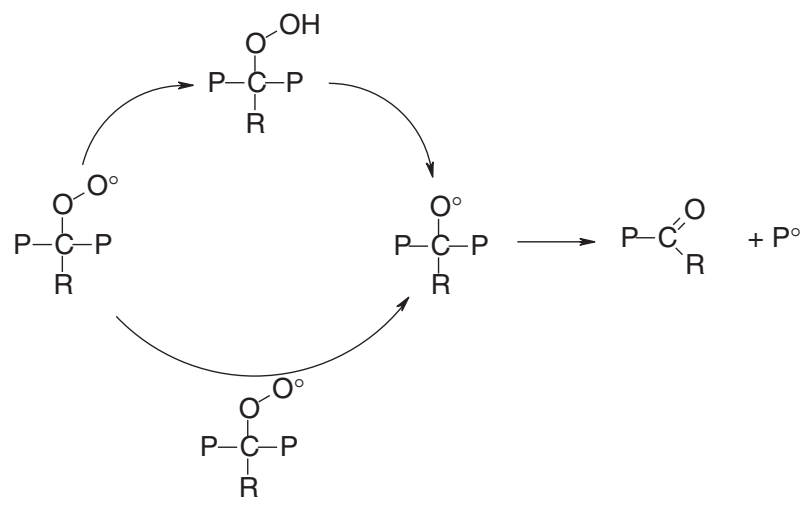

Figure 2

Main routes for oxidative chain scission in conditions of low temperature oxidation in dark.

The precursors of alkoxyls are peroxyls which are the chain carriers of radical oxidation. Peroxyls can give hydroperoxides $(\mathrm{POOH})$ in the propagation of radical chains. Hydroperoxides can decompose uni- or bimolecularly but in both cases they give alkoxyls. Peroxyls can also react with themselves. In most cases, the result of these bimolecular combinations is a termination but in some cases, alkoxy radicals can escape from the cage and initiate new radical chains abstracting hydrogens or rearranging by beta scission.

Let us consider both processes of alkoxyl formation:

$$
\delta \mathrm{POOH} \rightarrow \mathrm{PO}^{\circ}+\alpha \mathrm{HO}^{\circ}+\beta \mathrm{POO}^{\circ}
$$

and

$$
2 \mathrm{POO}^{\circ} \rightarrow \gamma \mathrm{PO}^{\circ}+\text { products }
$$

where $\alpha=1$ and $\beta=0$ if $\delta=1$ (unimolecular $\mathrm{POOH}$ decomposition); $\alpha=0, \beta=1$ if $\delta=2$ (bimolecular $\mathrm{POOH}$ decomposition). $\gamma$ must be derived from the kinetic analysis (see for instance Khelidj et al. [5]).

The beta scission of alkoxyls is in competition with other processes, e.g. $\mathrm{H}$ abstraction. A general expression of chain scission rate ( $s$ being the number of chain scissions per mass unit) would be thus:

$$
\frac{d s}{d t}=\gamma_{1} k_{1}[\mathrm{POOH}]^{\delta}+\gamma_{6} k_{6}\left[\mathrm{POO}^{\circ}\right]^{2}
$$

where $\gamma_{1}$ and $\gamma_{6}$ are yields to be determined experimentally. In many cases, the rates of $\mathrm{POOH}$ decomposition and $\mathrm{POO}^{\circ}$ bimolecular combination are almost equal (stationary state), so that it is licit to write simply:

$$
\frac{d s}{d t}=\gamma^{\prime} k_{1}[P O O H]^{\delta}
$$

Since each chain scission event creates a new chain, $s$ is linked to the number average molar mass by:

$$
s=\frac{1}{M_{n}}-\frac{1}{M_{n 0}}
$$

where $M_{n}$ and $M_{n 0}$ are the respective values of number average molar mass after and before ageing.

The link between oxidation kinetics and molar mass changes is now established. It remains to establish the link between molar mass and mechanical properties. What is clear is that chain scission favors fracture through chain disentanglement in the amorphous phase, but the embrittlement mechanism is not the same in amorphous or low crystallinity polar polymers and in non-polar highly crystalline polymers [6]. In the first category of polymers, for instance polycarbonate, poly(ethylene terephthalate) or polyamides, embrittlement results from the destruction of the entanglement network and occurs when the molar mass approaches the entanglement molar mass. In the second category, chain scission induces secondary crystallization (chemicrystallization); embrittlement occurs when the interlamellar spacing $l_{a}$ becomes lower than a critical value of the order of $6 \mathrm{~nm}$ in polyethylene [7] or polyoxymethylene [8]. However, since $l_{a}$ depends mainly of molar mass, it can be considered that embrittlement of polymers of the second category occurs, as for the first category, when the molar mass reaches a critical value $M_{c}{ }_{c}$. Both categories differ by the ratio critical molar mass / entanglement molar mass: $q=M_{c}{ }_{c} / M_{e}$.

$q \sim 2$ to 10 for the first category, typically $M_{c} \sim 15 \mathrm{~kg} / \mathrm{mol}$ for poly(ethylene terephthalate), polycarbonate or polyamide 11 and $q \sim 20$ to 50 for the second category, typically $M^{\prime}{ }_{c} \sim 70 \mathrm{~kg} / \mathrm{mol}$ for polyethylene and polyoxymethylene and $\sim 200 \mathrm{~kg} / \mathrm{mol}$ for polypropylene [9].

Ageing experiments are generally performed on unloaded samples and mechanical measurements are made at the end of exposure. This approach is justified when polymer parts don't sustain continuous loads in their use conditions. In this case, $M^{\prime}{ }_{c}$ constitutes a very good end-life criterion because when the molar mass approaches this value, the polymer toughness (Fig. 3a) and ultimate elongation (Fig. $3 b$ ) decay abruptly. This means that, when $M_{n}$ becomes lower than $M_{c}^{\prime}$, the probability of part failure under accidental loadings increases suddenly and approaches unity.

The problem is more complicated when the polymer sustains continuous static (creep) or dynamic (fatigue) loading. In such cases, chain disentanglement is favored by stress ("chain pulling"). Oxidative chain scission accelerates stress-cracking, but there is, to our knowledge, no consensus on the relationships between the time to fracture and the exposure and loading conditions. 

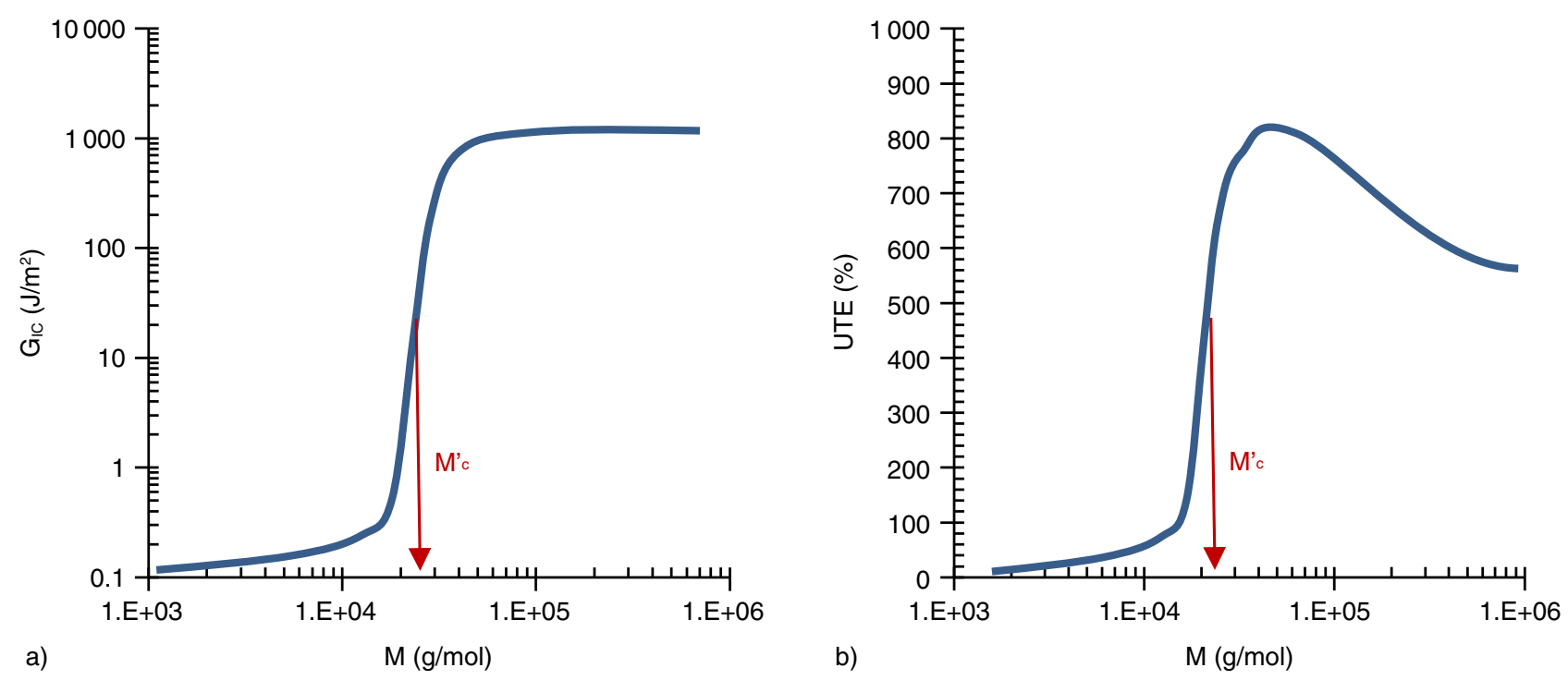

Figure 3

Shape of the molar mass dependance of toughness (here critical rate of elastic energy release for crack propagation in mode 1 a) and shape of the variation of ultimate tensile elongation against molar mass for a ductile polymer $b$ )). The scales are just shown to give the order of magnitude.

Transport properties (oxygen, stabilizers and oils) play a role in ageing kinetics. Do ageing modify transport properties? In principle, the solubility $(S)$ and diffusivity $(D)$ of small molecules in a polymer are not very sensitive to molar mass changes, at least above $M_{\mathrm{c}}$. But, in the case of hydrocarbon polymers, oxidation grafts polar groups (alcohols, ketones, acids, etc.) to the polymer. The polarity of this latter and thus its solubility parameter increases, which modifies the strength of polymer-small molecule interaction, with eventual consequences on solubility. Considering first fuel solubility in polyethylene (PE), we can predict opposite consequences of oxidation on hydrocarbon fuels and on ethanol. Hydrocarbon fuels have a solubility parameter close to polyethylene one, an increase of the PE solubility parameter due to oxidation is expected to increase the gap between PE and oil solubility parameters, the oil solubility is expected to decrease. Ethanol has a solubility parameter considerably higher than PE, and then PE oxidation is expected to increase ethanol solubility. Polarity changes are also expected to have consequences on the diffusivity of small molecules, as shown for water in PE by Mc Call et al. [10]. Theoretical tools are lacking to predict the effects of polarity changes on transport properties of all the mobile species under consideration. Here, in a first approach, it will be necessary to make experimental determinations on virgin and oxidized polymers and to derive empirical relationships from the results.

\subsection{Polymer - Biofuel Chemical Interaction}

When a biofuel is absorbed by a polymer, each BioFuel (BF) molecule is isolated from the others and surrounded by the Polymer Matrix (PM). Two cases can be distinguished:

- BF is considerably less reactive than PM to oxidation, in this case, BF doesn't influence significantly the polymer oxidation rate;

- BF is more reactive than PM. In this case, the question is: do the reactive species (radicals) resulting from BF oxidation attack PM? How to take into account such interactions in a kinetic model? Diesel biofuels are based on unsaturated esters as for instance mixtures of methyl esters of oleic, linoleic and linolenic acids. It is well known that methylenes are considerably more reactive in allylic placement than in a saturated chain. The reactivity is again increased when the methylene is placed between two double bonds, as in linoleic or linolenic esters. One can thus suspect an accelerating effect of these molecules on the oxidation of a saturated polymer matrix.

The problem of "co-oxidation" of mixtures of substrates having reactivities of the same order has been 
studied one half century ago [11] using solutions of the kinetic problem inspired by radical copolymerization theories. These solutions were based on a set of simplifying hypotheses among which the hypothesis of common initiation and termination and the hypothesis of stationary state. In such cases, the oxidation rate depends only on propagation rate constants (as reactivity ratios in copolymerization) and substrates concentrations. Here, we face more complex situations, for instance the existence of an induction period during which stationary state hypothesis cannot apply, and the complications linked to the presence of stabilizers. In the 1950-60s, the authors were forced to use simplifying hypotheses to obtain kinetic schemes having analytical solutions. Now, we can use numerical tools allowing the resolution of considerably more complex schemes without the recourse to these hypotheses [12]. In the frame of co-oxidation studies, it becomes possible to take into account polymer-biofuel interactions not only in propagation as in classical studies, but also in initiation and termination. An example of this new approach was recently given in the case of radiation initiated oxidation of ethylene-propylene copolymers [13]. In the case under study where a biofuel RH is mixed to a polymer $\mathrm{PH}$, the co-oxidation mechanistic scheme could be, assuming only bimolecular hydroperoxide decomposition and no presence of stabilizers:

$\begin{array}{ll}\mathrm{POOH}+\mathrm{POOH} \rightarrow \mathrm{P}^{\circ}+\mathrm{POO}^{\circ} & k_{111} \\ \mathrm{POOH}+\mathrm{ROOH} \rightarrow \mathrm{P}^{\circ}+\mathrm{ROO}^{\circ} & k_{112} \\ \mathrm{POOH}+\mathrm{ROOH} \rightarrow \mathrm{POO}^{\circ}+\mathrm{R}^{\circ} & k_{121} \\ \mathrm{ROOH}+\mathrm{ROOH} \rightarrow \mathrm{R}^{\circ}+\mathrm{ROO}^{\circ} & k_{122} \\ \mathrm{P}^{\circ}+\mathrm{O}_{2} \rightarrow \mathrm{POO}^{\circ} & k_{21} \\ \mathrm{R}^{\circ}+\mathrm{O}_{2} \rightarrow \mathrm{ROO} & k_{22} \\ \mathrm{POO}^{\circ}+\mathrm{PH} \rightarrow \mathrm{POOH}+\mathrm{P}^{\circ} & k_{311} \\ \mathrm{POO}^{\circ}+\mathrm{RH} \rightarrow \mathrm{POOH}+\mathrm{R}^{\circ} & k_{312} \\ \mathrm{ROO}^{\circ}+\mathrm{PH} \rightarrow \mathrm{ROOH}+\mathrm{P}^{\circ} & k_{321} \\ \mathrm{ROO}^{\circ}+\mathrm{RH} \rightarrow \mathrm{ROOH}+\mathrm{R}^{\circ} & k_{322} \\ \mathrm{P}^{\circ}+\mathrm{P}^{\circ} \rightarrow \mathrm{Inact} \text { Prod. } & k_{411} \\ \mathrm{P}^{\circ}+\mathrm{R}^{\circ} \rightarrow \mathrm{Inact} \text { Prod. } & k_{412} \\ \mathrm{R}^{\circ}+\mathrm{R}^{\circ} \rightarrow \mathrm{Inact} \text { Prod. } & k_{422} \\ \mathrm{POO}^{\circ}+\mathrm{P}^{\circ} \rightarrow \text { Inact. Prod. } & k_{511} \\ \mathrm{POO}^{\circ}+\mathrm{R}^{\circ} \rightarrow \text { Inact. Prod. } & k_{512} \\ \mathrm{ROO}^{\circ}+\mathrm{P}^{\circ} \rightarrow \text { Inact. Prod. } & k_{521} \\ \mathrm{ROO}^{\circ}+\mathrm{R}^{\circ} \rightarrow \text { Inact. Prod. } & k_{522} \\ \mathrm{POO}^{\circ}+\mathrm{POO}^{\circ} \rightarrow \text { Inact. Prod. }+\mathrm{O}_{2} & k_{611} \\ \mathrm{POO}^{\circ}+\mathrm{ROO}^{\circ} \rightarrow \text { Inact. Prod. }+\mathrm{O}_{2} & k_{612} \\ \mathrm{ROO}^{\circ}+\mathrm{ROO}^{\circ} \rightarrow \text { Inact. Prod. }+\mathrm{O}_{2} & k_{622}\end{array}$

This scheme involves 21 elementary rate constants plus some stoichiometric yield ratios, it is clearly out of reach of analytical resolutions but it can be solved numerically using commercial solvers. All the rate constants $k_{i 11}$ relative to the polymer oxidation are already known $[1,5]$. Many rate constants relative to unsaturated fatty esters can be found in literature; the rest must be experimentally determined. Concerning the rate constants of cross reactions ( $k_{i 12}$ and $\left.k_{i 21}\right)$ they can be estimated, starting from the idea that they are intermediary between both corresponding "homo-oxidation" rate constants, using for instance the already used geometric average: $k_{i 12}=$ $\left(k_{i 11} \cdot k_{i 22}\right)^{1 / 2}$.

In the final step of the model elaboration, stabilization reactions will be added to the above scheme and oxygen and stabilizer(s) diffusion terms will be added to kinetic equations. Indeed, diffusion terms must take into account the eventual role of oil penetration in the polymer. The resulting scheme is among the most complex ones in the field of oxidation of substrates in solid state.

\subsection{Principles of Lifetime Prediction}

In the case of polymer automotive parts in contact with fuels, not submitted to solar (UV) irradiation, the first factor to consider in a durability analysis is the existence or not of continuous mechanical (static or dynamic) loading.

If the parts are not loaded or sustain low stress levels, for instance $\leq 10 \%$ of instantaneous yield stress, failure can only result from a deep embrittlement due to chemical degradation, i.e. oxidation. Then, the parts can undergo fracture under low level stresses linked to small impacts or simply from differential dilatations induced by temperature changes. The most pertinent end-life criterion is then the embrittlement critical molar mass $M_{c}$. From fracture mechanics concepts, one can determine the critical thickness $l_{c}$ of the brittle layer able to induce crack propagation in the whole sample thickness $[14,15]$. The oxidation kinetic model with reaction-diffusion coupling is aimed to predict at every moment the thickness distribution of average molar mass $M$. The end of life corresponds to the moment where $M=M_{c}^{\prime}$ at the depth $l_{c}$. This criterion doesn't predict the part fracture but rather the moment at which the probability of part fracture increases suddenly to approach unity.

If the parts sustain continuous loads, two subcases can be envisaged depending on the occurrence or not of chemical degradation (i.e. oxidation). Let us call $\sigma$ the stress (static creep) or the stress amplitude (fatigue), the curves of lifetime $t_{f}$ against $\sigma$ are expected to have the shape of Figure 4.

In the absence of chemical degradation, there is a critical stress $\sigma_{c}$ below which there is no fracture. The value of $\sigma_{c}$ depends of temperature and fluids in contact. A decrease of $\sigma_{c}$ is thus expected in the presence of oil, its amplitude depends mainly of the difference of solubility 


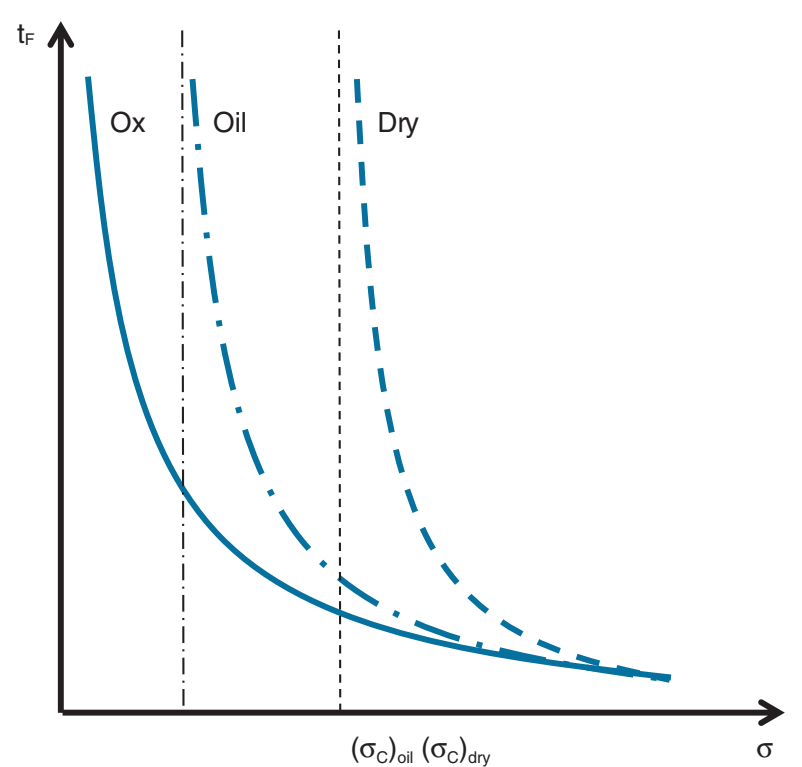

Figure 4

Shape of lifetime-stress curves in the presence ("ox") or the absence of oxygen ("oil" in the presence of oil; "dry" in the absence of oil) of chemical degradation.

parameters between the polymer and oil. The viscosity and surface tension of this latter, which determines the rate at which oil reaches the crack tip, can also play a role. These phenomena are well understood from a qualitative point of view, but there is no, to our knowledge, consensus on the mathematical expression of the curves $t_{f}=f(\sigma)$.

In the presence of chemical degradation, at high stress levels, failure occurs before significant chemical changes, the curve $t_{f}=f(\sigma)$ is superposed to the curves corresponding to the absence of degradation (obtained for instance in neutral atmosphere). At low stress levels, i.e. at longer exposure times, degradation affects the polymer strength, the curve diverges from preceding ones and does not display an asymptotic stress. Here, again, there is no wide consensus on the kinetic modeling approach. The following approach has been recently proposed by Colin et al. [16].

Let us consider a polymer sample of thickness $L$ submitted to a constant tensile stress $\sigma$ in the presence of oxygen at constant temperature $T$. A model of lifetime prediction can be built associating three "moduli": the first one relative to polymer degradation, aimed to determine the thickness distribution of average molar mass at every time; the second one relative to polymer creep kinetics and the third one relative to the molar mass dependence of ultimate strain $\varepsilon_{R}$. The principles involved can be described as follows:
The sample undergoes a creep characterized by an anelastic strain rate $d \varepsilon / d t$ depending of the applied stress, temperature and time. A very simple equation was proposed by the authors:

$$
d \varepsilon / d t=A e_{T} \cdot \sigma \cdot t^{-m}
$$

where $A$ is a constant, $e_{T}$ is a temperature factor obeying for instance Arrhenius law: $e_{T}=\exp -(H / R T)$ and $m$ is an exponent expressing the auto-retardated character of creep. The integration of this equation gives the anelastic strain $\varepsilon=f(t)$.

The fracture behavior of the polymer is characterized by the existence of a relatively sharp ductile-brittle transition. It is generally considered that ductility is due to the existence of an entanglement network in the polymer amorphous phase. Under the combined effect of stress and temperature, the chains are mobile enough to disentangle by reptation but the time to disentanglement varies rapidly with molar mass, roughly:

$$
t \text { (disent.) } \sim \mathrm{M}^{3}
$$

NB: This time is shortened by the plasticizing effect of absorbed fuels.

Thus the sample deforms continuously under the effect of applied stress but becomes abruptly brittle when the time approaches the disentanglement. This disentanglement time decreases rapidly when molar mass decreases as a result of oxidation. As it has been shown above, in a thick sample, fracture will become highly probable when the disentanglement time will be reached at the critical depth $l_{c}$ depending on polymer fracture properties; in polyethylene for instance, $l_{c} \sim 100 \mu \mathrm{m}$.

Other approaches, based for instance on considerations of crack propagation, are possible in the case of glassy polymers [17].

\section{POLYETHYLENE AGEING IN CONTACT WITH BIOETHANOL}

\subsection{Polyethylene Stabilization}

Stabilizers are incorporated into polymers to reduce oxidative degradation, during processing and in the subsequent service life of the polymer. Processing stabilization of polyethylene is usually done by combination of phenolic and phosphorous antioxidants [18-21]. Fearon et al. [22] attributed the positive effect of phosphite antioxidants to their interaction with peroxides; the trivalent phosphorous additives often help to improve the colour of polymers. Indeed, organic phosphites have been applied as efficient processing stabilizers 

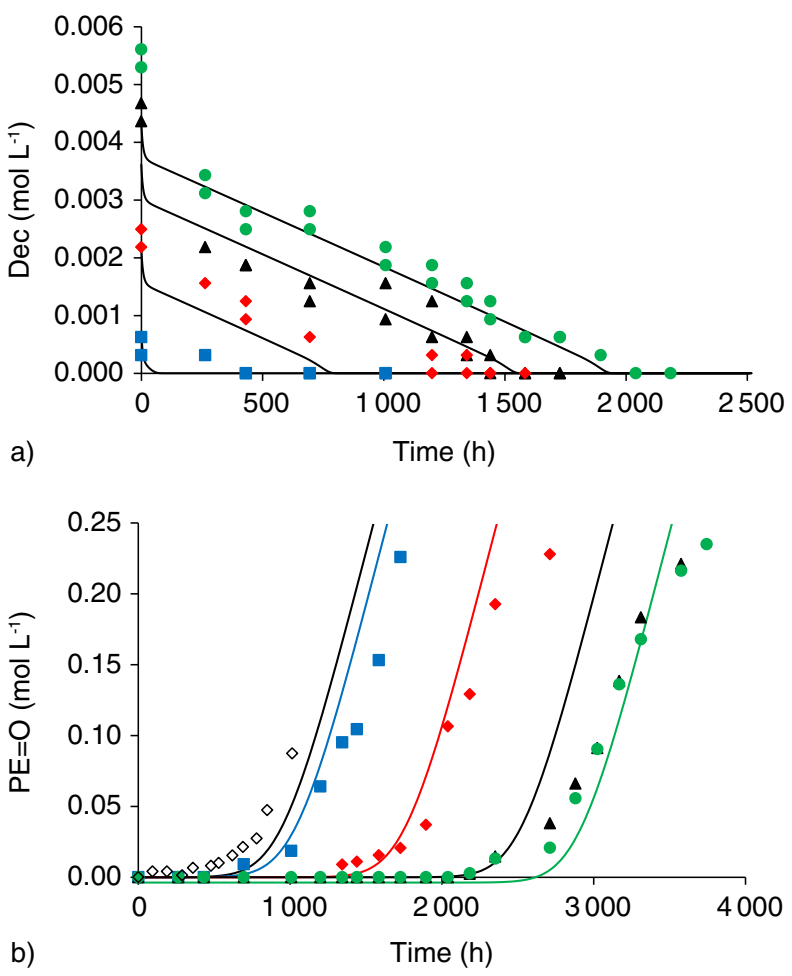

Figure 5

Kinetics of phosphite depletion a) and carbonyl build up b) for pure PE $(\diamond), \mathrm{PE}+0.1 \%$ Irgafos $168(\mathbf{\square})$, $\mathrm{PE}+0.2 \%$ Irgafos $168(\diamond), \mathrm{PE}+0.3 \%$ Irgafos $168(\boldsymbol{\Delta})$, $\mathrm{PE}+0.4 \%$ Irgafos $168(\bullet)$ at $80^{\circ} \mathrm{C}$ (full lines correspond to kinetic modeling - see [22]).

in numerous polymers, especially polyolefins. Various mechanisms of phosphite stabilization have been proposed in the literature [23, 24]. Here, in order to put in evidence the major pathway of phosphite consumption, we present some results obtained at moderate temperatures $\left(\leq 180^{\circ} \mathrm{C}\right)$ for ageing of a pure polyethylene mixed with $0.1,0.2,0.3$ or $0.4 \%$ of an organophosphite stabilizer Irgafos 168 [1]. An FTIR study confirmed that, in the conditions under study, this phosphite is consumed by reducing hydroperoxides and yields a phosphate. When phosphites (or more generally all sacrificial stabilizers) are totally consumed (Fig. 5b), the sudden auto-acceleration of oxidation takes place (Fig. 5a) and embrittlement occurs shortly after. It was also shown that adding $0.4 \%$ (in weight) of phosphite permitted to increase the lifetime of $\mathrm{PE}$ at $80^{\circ} \mathrm{C}$ from less than 1 $000 \mathrm{~h}$ to more than $2000 \mathrm{~h}$. The non-linear change of induction period with the concentration in phosphites can be interpreted as the consequence of a partial loss of stabilizer by evaporation, which is completely modeled elsewhere [1].

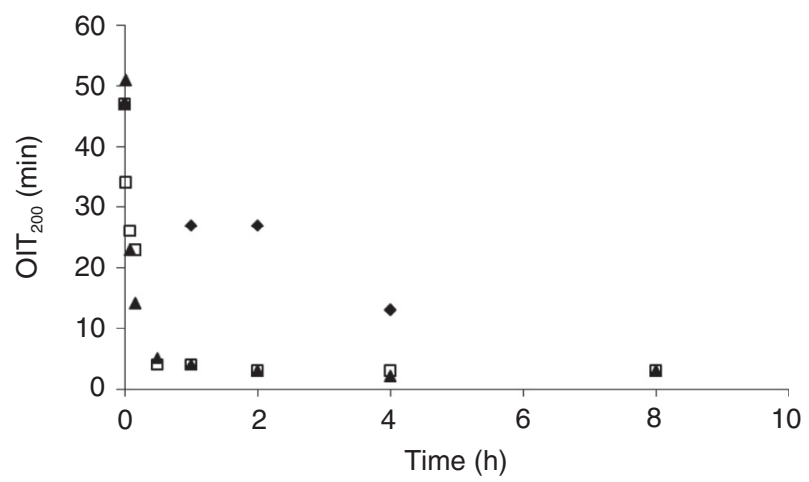

Figure 6

$\mathrm{OIT}_{200}$ variation for the commercial sample exposed in ethanol $(\diamond)$, E10 $(\square)$ and E50 $(\mathbf{\Delta})$ at $80^{\circ} \mathrm{C}$.

Hindered phenols are intrinsically more efficient than phosphites, for instance, lifetimes of the order of more than $10000 \mathrm{~h}$ can be expected for PE + some ppm of Irganox 1010 [25]. It means that phenol + phosphite stabilized PE is expected to keep its engineering properties over years provided stabilizers disappear only by chemical consumption (radicals or hydroperoxides trapping). Let us now turn to the possible influence of fuel-medium environment likely to promote physical loss.

\subsection{Experimental Evidence for Stabilizer Loss in the Presence of Ethanol}

It has been tried to appreciate an eventual effect of ethanol based fuels on the oxidative stability of stabilized PE, focusing on stabilizer extraction by the fuel. A commercial HDPE sample stabilized by a phenol-phosphite synergistic blend was immersed in ethanol-cyclohexane mixtures used as model fuels (denoted by E0, E10 or E50, the number expressing the volume ratio of ethanol) at $80^{\circ} \mathrm{C}$ (Fig. 6) [2].

Polyethylene and common hydrocarbon fuels have relatively close solubility parameters, typically of the order of (15.8 to $17.1 \mathrm{MPa}^{1 / 2}$ ). Phenolic and phosphites stabilizers have noticeably higher solubility parameters. Ethanol is more polar than the stabilizers under study $\left(26.3 \mathrm{MPa}^{1 / 2}\right)$. Stabilizers are expected to be more soluble in ethanol than in PE so that one could expect a negative effect of ethanol on PE durability owing to its eventual extractive power on stabilizers.

To check this hypothesis, samples were immersed in various ethanol-cyclohexane mixtures and the stabilizer disappearance was monitored by Oxidation Induction Time (OIT) measurements (length of oxidation period 

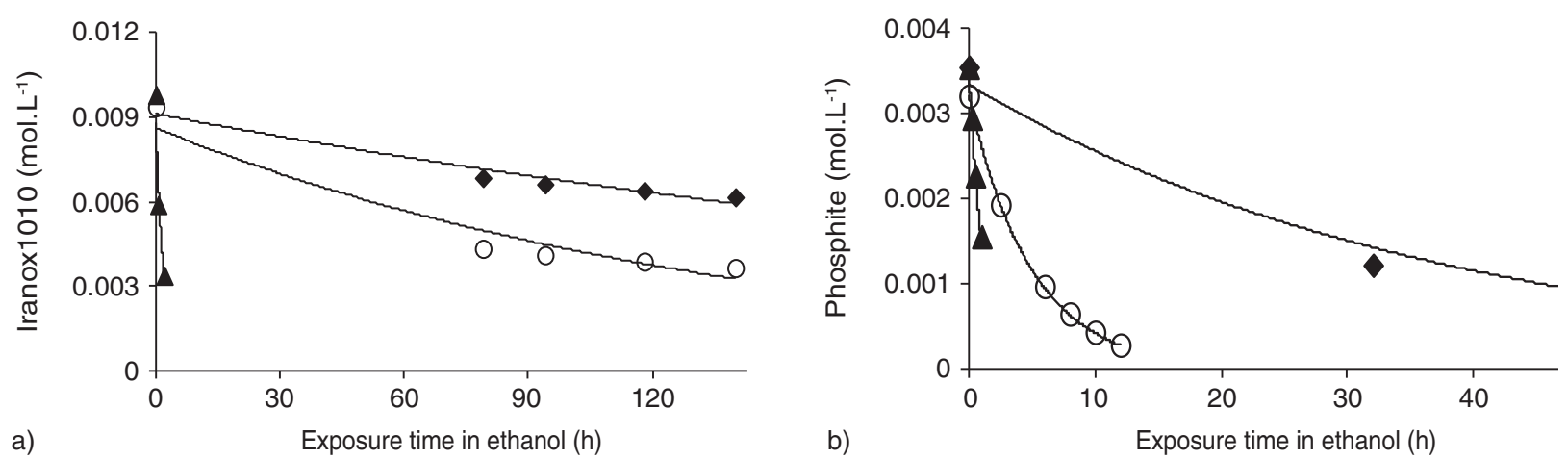

Figure 7

Exposure of laboratory made samples stabilized by Irganox 1010 a) and Irgafos $168 \mathrm{~b}$ ) stabilizer loss at $40^{\circ} \mathrm{C}(\bullet), 60^{\circ} \mathrm{C}()$ and $80^{\circ} \mathrm{C}(\boldsymbol{\Delta})$ in pure ethanol.

TABLE 1

Molar mass and apparent first order rate constants for Irgafos 168 and Irganox 1010 at various temperatures and apparent activation energy $\left(E_{a}\right)$

\begin{tabular}{c|c|c|c|c|c}
\hline & & \multicolumn{3}{|c|}{ Rate constant $\beta\left(\mathrm{h}^{-1} \times 10^{-2}\right)$} & $80^{\circ} \mathrm{C}$ \\
\hline & $\mathrm{M}\left(\mathrm{g} . \mathrm{mol}^{-1}\right)$ & $40^{\circ} \mathrm{C}$ & $60^{\circ} \mathrm{C}$ & $E_{a}\left(\mathrm{~kJ} . \mathrm{mol}^{-1}\right)$ \\
\hline Irgafos 168 & 647 & 2.7 & 20 & 84 & $90 \pm 10$ \\
\hline Irganox 1010 & 1178 & 0.33 & 1.3 & 25 & $110 \pm 10$ \\
\hline
\end{tabular}

recorded in situ for an isothermal ageing test under $100 \%$ oxygen at atmospheric pressure, at 190 or $200^{\circ} \mathrm{C}$ in the DSC cell), assumed to be proportional to the residual quantity of stabilizers after ageing. Some results obtained at $80^{\circ} \mathrm{C}$ are shown in Figure 6 . They call for the following comments:

Immersion in fuel drastically increases the stabilizer loss rate. Phosphite and phenol concentrations tend towards 0 after respectively c.a. 50 and $100 \mathrm{~h}$. Thus alcohol-hydrocarbon fuels are expected to decrease the PE oxidative stability in proportion depending, indeed, of temperature and sample thickness.

Stabilizer extraction appears considerably slower in pure ethanol than in ethanol-cyclohexane mixtures.

Concerning the latter, no significant difference was found between E10 and E50. Extraction rate was in any case lowered when fuel is mixed with ethanol. One can thus conclude that bioethanol doesn't negatively influence the ageing behavior of polyethylene parts.

\subsection{Modeling Aspects for Stabilizer Depletion}

It seemed to us interesting to appreciate the extractive power of pure ethanol for samples containing a single stabilizer (here made of an additive free PE grade mixed with $0.3 \%$ Irganox 1010 or $0.3 \%$ Irgafos 168 prepared as described in [1, 2]). For those stabilizers, the concentration can be easily monitored by FTIR $[1,2]$. The results of immersion tests at 40,60 and $80^{\circ} \mathrm{C}$ showed that stabilizer loss obeys first order kinetics:

$$
\frac{d O I T}{d t}=-\beta\left(O I T-O I T_{\infty}\right)
$$

where $O I T_{\infty}$ is the induction time of the non-stabilized polymer and $\beta$ is a first order rate constant.

The loss rate is significantly higher for Irgafos 168 than for Irganox 1010 that can be explained by the well-known effect of molar mass on migration rate [26].

Then the work is focused on the study of the depletion of each stabilizer separately. The results argue for a first order kinetics (Fig. 7).

Apparent first-order rate constant values $\beta$ for stabilizer loss at 40,60 and $80^{\circ} \mathrm{C}$ were determined. They are compiled in Table 1.

It can be verified that $\beta$ obeys Arrhenius law, which allows extrapolating at lower temperature to perform some prediction of extraction kinetics in the device temperature range. Those values can now be used in a model coupling extraction of stabilizer in the sample superficial layer and diffusion from the bulk.

By comparing a characteristic time for extraction $\tau_{E}=1 / \beta$ with the diffusion characteristic time $\tau_{D}=L^{2} / D, L$ being the sample thickness, it seems however, that stabilizer migration in the external fuel media is a diffusion controlled phenomena [2]. 


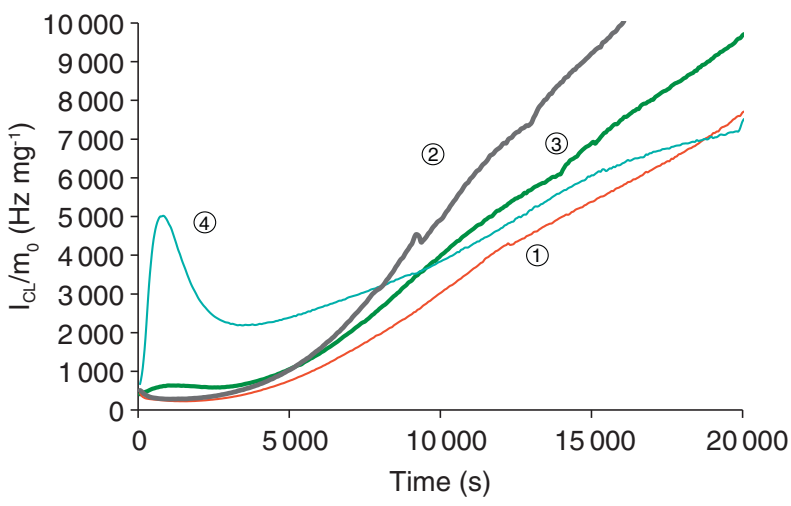

Figure 8

Kinetic curves of chemiluminescence emission for thermal oxidation at $150^{\circ} \mathrm{C}$ of pure $\mathrm{PE}$ (1), $\mathrm{PE}+$ methyl oleate (2), $\mathrm{PE}+$ methyl linoleate (3) and PE + methyl linolenate (4).

\section{POLYETHYLENE AGEING IN CONTACT WITH BIODIESELS}

\subsection{Experimental Evidence for Co-Oxidation}

Let us first recall that biodiesel from vegetable source are mixtures of 16 or 18 carbon fatty acids with $0,1,2$ or 3 doubles bonds [27]. It seemed to us interesting to study polymer-biodiesel interaction through the case of $\mathrm{PE}$ ageing in presence of methyl oleate, linoleate or linolenate chosen as model systems. Stabilizer free PE films were impregnated with those methyl esters at room temperature. Let us precise that this study was just aimed at highlighting a possible co-oxidation, that leads to the choice of a non-stabilized PE rather than a commercial one. These films were then submitted to thermo-oxidative ageing at $150^{\circ} \mathrm{C}$ and the oxidation rate was monitored in situ by ChemiLuminescence (CL) measurements. Typical CL results are presented in Figure 8. They call for the following comments:

- for pure PE: the curve has the classical sigmoidal shape. A small shoulder at time $\sim 10000 \mathrm{~s}$ is noticed. According to Broska and Rychly [28], it could be due to the existence of structural irregularities in PE. This interpretation is, as it will be seen after, in good agreement with the proposal of kinetic model for co-oxidation involving the role of double bonds;

- for PE + methyl oleate and PE + methyl linoleate, the CL kinetic curve is progressively shifted towards shorter times, suggesting that PE matrix is oxidized faster in the presence than in the absence of unsaturated ester (UFE). A small CL peak appearing in the early times of exposure can be suspected for $\mathrm{PE}+$ methyl linoleate;

- the trends observed for the PE + methyl linoleate are strongly exaggerated for the PE + methyl linolenate system where an intense peak develops in the early hours of exposure and where the light emission in the first 5000 seconds is considerably stronger than for the other samples.

It can be shown that pure methyl esters of unstatturated fatty acid oxidize faster than PE. Figure 8 could be considered as the overlap of PE oxidation curve and UFE one. The shift of the part of curve ascribed to PE observed when this latter has been impregnated by UFE militates in favor of a cooxidation process, i.e. that UFE oxidation generates some radical species attacking PE chains. Some complementary experiments made on PE in solid state $\left(T<130^{\circ} \mathrm{C}\right)$ were aimed at deconvoluting the overall carbonyl concentration into the part generated from UFE and the part attibuted to pure PE oxidation [4]. The results clearly showed that the presence of unsaturated fatty esters accelerates the oxidation kinetics of PE matrix because the UFE are more oxidizable than PE due to their allylic hydrogens. We will now try to derive a kinetic modeling permitting to simulate this striking fact.

\subsection{Co-Oxidation Modeling Aspects}

It is now well established that the oxidative degradation of additive free PE can be described by the following kinetic model [5]:

\begin{tabular}{|c|c|}
\hline (1u) & $\mathrm{PE}-\mathrm{OOH} \rightarrow 2 \mathrm{PE}^{\circ}+\gamma_{\mathrm{CO}} \mathrm{PE}=\mathrm{O}+\gamma_{\mathrm{s}} \mathrm{s}$ \\
\hline (1b) & $2 \mathrm{PE}-\mathrm{OOH} \rightarrow \mathrm{PE}^{\circ}+\mathrm{PE}-\mathrm{OO}^{\circ}+\gamma_{\mathrm{CO}} \mathrm{PE}=\mathrm{O}+\gamma_{\mathrm{s}} \mathrm{s}$ \\
\hline (2) & $\mathrm{PE}^{\circ}+\mathrm{O}_{2} \rightarrow{\mathrm{PE}-\mathrm{OO}^{\circ}}^{\circ}$ \\
\hline (3) & $\mathrm{PE}-\mathrm{OO}^{\circ}+\mathrm{PEH} \rightarrow \mathrm{PE}-\mathrm{OOH}+\mathrm{PE}^{\circ}$ \\
\hline (4) & $\mathrm{PE}^{\circ}+\mathrm{PE}^{\circ} \rightarrow$ inactive products \\
\hline (5) & 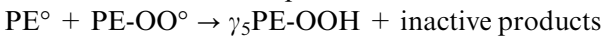 \\
\hline (6) & ${\mathrm{PE}-\mathrm{OO}^{\circ}}^{\circ}{\mathrm{PE}-\mathrm{OO}^{\circ} \rightarrow \text { inactive products }}+\mathrm{O}_{2}$ \\
\hline
\end{tabular}

where: $k_{1 \mathrm{u}}$ is the rate constant for unimolecular hydroperoxide decomposition $\left(\mathrm{s}^{-1}\right) ; k_{1 \mathrm{~b}}, \ldots, k_{6}$ are second order rate constants for bimolecular processes $\left(\mathrm{L} . \mathrm{mol}^{-1} . \mathrm{s}^{-1}\right) ; \gamma_{\mathrm{CO}}, \gamma_{\mathrm{S}}$ and $\gamma_{5}$ are respectively yields in carbonyl, chain scission and hydroperoxides for $(1 \mathrm{u})$, (1b), (5) and (6) equations. Here, reaction 6 is a virtual balance equation kinetically equivalent to several coexisting termination reactions (coupling, disproportionation, etc.) [5].

The ratio $k_{3}^{2} / k_{6}$ expresses the intrinsic substrate oxidizability, independent of the initiation mode (peroxide decomposition, polymer radiolysis or photolysis, etc.) [1]. In the case of ethylene propylene co-oxidation, Decker et al. [29] showed that the oxidizability ratio 
varies with ethylene molar fraction $e$ according to a pseudo-hyperbolic curve which could be approximated by the following function:

$$
\frac{k_{3}}{\sqrt{k_{6}}}=10^{-4} \times \frac{2-1.63 \times e}{1+3.13 \times e}
$$

where $k_{3}$ and $k_{6}$ can be defined as the rate constants characteristic of a virtual homopolymer which would have the same kinetic behavior as the copolymer under study. An approach in which the kinetic behavior of the copolymer would be predicted from the characteristics of the corresponding homopolymers would be, indeed, more satisfactory. Such an approach needs to solve the co-oxidation kinetic scheme in which there are two distinct reactive sites: here tertiary carbons present only in propylene units and secondary carbons present in both comonomers are simultaneously oxidized (oxidation of primary carbons of propylene units can be neglected).

The presence of two reactive sites needs to take into account supplementary reaction for cross initiation, propagation, termination to be added to the selfinitiation, propagation and termination reactions for pure substrates. If $\mathrm{PE}$ represents the aliphatic $\left(-\mathrm{CH}_{2}-\right)$ substrate (for polymer matrix) and UFE the allylic $>\mathrm{C}=\mathrm{CH}-\mathrm{CH}_{2-}$ one (for methyl ester), the kinetic scheme could be written:

\begin{tabular}{|c|c|}
\hline (I-b11) & $\mathrm{UFE}-\mathrm{OOH}+\mathrm{UFE}-\mathrm{OOH} \rightarrow \mathrm{UFE}^{\circ}+\mathrm{UFE}^{-O O^{\circ}}+\mathrm{UFE}=\mathrm{O}$ \\
\hline (I-b12) & $\mathrm{UFE}-\mathrm{OOH}+\mathrm{PE}-\mathrm{OOH} \rightarrow \mathrm{PE}^{\circ}+\mathrm{UFE}^{\circ} \mathrm{OO}^{\circ}+\mathrm{UFE}=\mathrm{O}$ \\
\hline$(\mathrm{I}-\mathrm{u} 2)$ & $\mathrm{PE}-\mathrm{OOH} \rightarrow 2 \mathrm{PE}^{\circ}+\gamma_{\mathrm{CO}} \mathrm{PE}=\mathrm{O}+\gamma_{\mathrm{S}} \mathrm{S}$ \\
\hline (I-b22) & 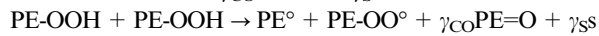 \\
\hline (II-1) & $\mathrm{UFE}^{\circ}+\mathrm{O}_{2} \rightarrow \mathrm{UFE}-\mathrm{OO}^{\circ}$ \\
\hline (II-2) & $\mathrm{PE}^{\circ}+\mathrm{O}_{2} \rightarrow \mathrm{PE}-\mathrm{OO}^{\circ}$ \\
\hline (III-11) & $\mathrm{UFE}^{-O O}+\mathrm{UFE}-\mathrm{H} \rightarrow \mathrm{UFE}-\mathrm{OOH}+\mathrm{UFE}^{\circ}$ \\
\hline (III-12) & $\mathrm{UFE}^{-O O}{ }^{\circ}+\mathrm{PE}-\mathrm{H} \rightarrow \mathrm{UFE}-\mathrm{OOH}+\mathrm{PE}^{\circ}$ \\
\hline (III-21) & $\mathrm{PE}-\mathrm{OO}^{\circ}+\mathrm{UFE}-\mathrm{H} \rightarrow \mathrm{PE}-\mathrm{OOH}+\mathrm{UFE}^{\circ}$ \\
\hline (III-22) & $\mathrm{PEOO}^{\circ}+\mathrm{PEH} \rightarrow \mathrm{PEOOH}+\mathrm{PE}^{\circ}$ \\
\hline (VI-11) & $\mathrm{UFE}-\mathrm{OO}^{\circ}+\mathrm{UFE}^{-\mathrm{OO}^{\circ}} \rightarrow$ inactive product \\
\hline (VI-12) & $\mathrm{UFE}^{-O O}{ }^{\circ}+\mathrm{PE}-\mathrm{OO}^{\circ} \rightarrow$ inactive product \\
\hline (VI-22) & $\mathrm{PE}-\mathrm{OO}^{\circ}+\mathrm{PE}-\mathrm{OO}^{\circ} \rightarrow$ inactive product \\
\hline
\end{tabular}

Similar models were presented in literature for extrinsically initiated oxidation. They were analytically solved using ad hoc hypothesis (for example equality of cross propagation rates $r_{312}=r_{321}$ ) and under the assumption of constant initiation rate (which is not suitable for thermal oxidation). Here, we will check this model on PE + methyl esters of unsaturated esters of oleic, linoleic or linolenic acids, these latter being expected to have distinct oxidizabilities and also to oxidize faster than PE. The use of a numerical tool will permits to solve the system of differential equations without using questionable hypotheses and also to generate a wide variety of simulations to be compared with our experimental results, in particular here the non-monotonous shape of CL curves.
The simulations runs were done using the following hypotheses:

$-k_{21}$ was chosen equal to $10^{7} \mathrm{~L} \cdot \mathrm{mol}^{-1} \cdot \mathrm{s}^{-1}$, having in mind that variations of this value have a negligible influence on oxidation kinetics. It seems reasonable to assume $k_{21}<k_{22}$ because of the difference of reactivity between $\mathrm{PE}^{\circ}$ and $\mathrm{UFE}^{\circ}$ alkyl radicals;

$-k_{\mathrm{b} 11}$ and $k_{611}$ have been here fixed respectively equal to $10^{-2}$ and $10^{8} \mathrm{~L} \cdot \mathrm{mol}^{-1} \cdot \mathrm{s}^{-1}$. Their precise adjustment from the CL curves of pure methyl esters oxidation is under study in our lab;

- Cross initiation and cross termination rate constants were calculated under the assumption of geometrical means:

$$
\begin{aligned}
& k_{612}^{2}=k_{611} \times k_{622} \\
& k_{\mathrm{b} 12}{ }^{2}=k_{\mathrm{b} 11} \times k_{\mathrm{b} 22}
\end{aligned}
$$

$-k_{31}, k_{312}, k_{32}, k_{321}$ for the reaction:

$\mathrm{ROO}^{\circ}+\mathrm{PH} \rightarrow \mathrm{ROOH}+\mathrm{P}^{\circ}$

propagation reactions can be calculated by the relationships established by Korcek et al. [30]:

$$
\begin{gathered}
\log _{10} k_{p}{ }^{\mathrm{sec}-\mathrm{ROO}^{\circ}}\left(30^{\circ} \mathrm{C}\right)=16.4-0.2 \times \mathrm{BDE}(\mathrm{C}-\mathrm{H}) \\
E_{P}=0.55 \times(\mathrm{BDE}(\mathrm{C}-\mathrm{H})-62.5)
\end{gathered}
$$

where ${ }^{\text {sec-ROO}}{ }^{\circ}$ denotes a secondary peroxy radical, $\mathrm{BDE}(\mathrm{C}-\mathrm{H})$ is the bond dissociation energy (in kcal. $\mathrm{mol}^{-1}$ ) of an abstractable hydrogen hold by a $\mathrm{P}-\mathrm{H}$ substrate.

Using these relationships together with BDE values reported by Denisov [31] for several unsaturated hydrocarbons, propagation rate constants values at $150^{\circ} \mathrm{C}$ can be proposed (Tab. 2).

Since the propagation rate constants depend only on the bond dissociation energy of broken $\mathrm{C}-\mathrm{H}$ bond, we will first assume:

$$
\begin{aligned}
& k_{312}=k_{322} \\
& k_{321}=k_{311}
\end{aligned}
$$

(instead of equality of the rates:

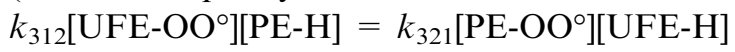

as done in the original paper by Russell [11]).

The following initial conditions were chosen:

$$
\begin{gathered}
{\left[\mathrm{PE}^{\circ}\right]_{0}=\left[\mathrm{PEOO}^{\circ}\right]_{0}=\left[\mathrm{UFE}^{\circ}\right]_{0}=\left[\mathrm{UFE}-\mathrm{OO}^{\circ}\right]_{0}=0} \\
{[\mathrm{PEOOH}]_{0}=10^{-4} \mathrm{~mol} . \mathrm{L}^{-1},[\mathrm{UFEOOH}]_{0}=10^{-2} \mathrm{~mol} . \mathrm{L}^{-1}} \\
{[\mathrm{PH}]_{0}=60 \mathrm{~mol} . \mathrm{L}^{-1},[\mathrm{UFE}-\mathrm{H}]_{0}=0.3 \mathrm{~mol} . \mathrm{L}^{-1}}
\end{gathered}
$$

calculated as the number of moles of the more reactive hydrogens present in the c.a. $5 \%$ fatty ester absorbed 
TABLE 2

Kinetic parameters of propagation reactions in saturated and unsaturated substrates

\begin{tabular}{|c|c|c|c|c|}
\hline & $\mathrm{BDE}(\mathrm{C}-\mathrm{H})\left(\mathrm{kJ} \cdot \mathrm{mol}^{-1}\right)$ & $E_{3}\left(\mathrm{~kJ} \cdot \mathrm{mol}^{-1}\right)$ & $k_{3}\left(30^{\circ} \mathrm{C}\right)\left(\mathrm{L}^{\mathrm{mol}}{ }^{-1} \cdot \mathrm{s}^{-1}\right)$ & $k_{3}\left(150^{\circ} \mathrm{C}\right)\left(\mathrm{L} \mathrm{mol}^{1} \cdot \mathrm{s}^{-1}\right)$ \\
\hline$\lambda$ & 395.5 & 73.7 & 0.0 & 12.6 \\
\hline $\mathrm{CH}_{2}=\mathrm{CHCH}_{2}-\mathrm{H}$ & 368 & 58.5 & 0.1 & 47.2 \\
\hline $\mathrm{CH}_{2}=\mathrm{CH}(\mathrm{CH}-\mathrm{H}) \mathrm{Me}$ & 349.8 & 48.5 & 0.5 & 113.4 \\
\hline $\begin{array}{c}\mathrm{Z}-\mathrm{MeCH}=\mathrm{CH}(\mathrm{CH}-\mathrm{H}) \\
\mathrm{Me}\end{array}$ & 344 & 45.3 & 0.9 & 149.9 \\
\hline $\mathrm{Me}_{2} \mathrm{C}=\mathrm{CH}(\mathrm{CH}-\mathrm{H}) \mathrm{Me}$ & 332 & 38.7 & 3.4 & 267.2 \\
\hline $\mathrm{Me}_{2} \mathrm{C}=\mathrm{CH}(\mathrm{C}-\mathrm{H}) \mathrm{Me}_{2}$ & 322.8 & 33.7 & 9.4 & 416.2 \\
\hline $\mathrm{H}-\mathrm{H}$ & 341.5 & 44.0 & 1.2 & 169.1 \\
\hline & 330.9 & 38.1 & 3.9 & 281.8 \\
\hline & 312.6 & 28.1 & 28.9 & 680.2 \\
\hline & 301 & 21.7 & 103.6 & 1189.1 \\
\hline
\end{tabular}
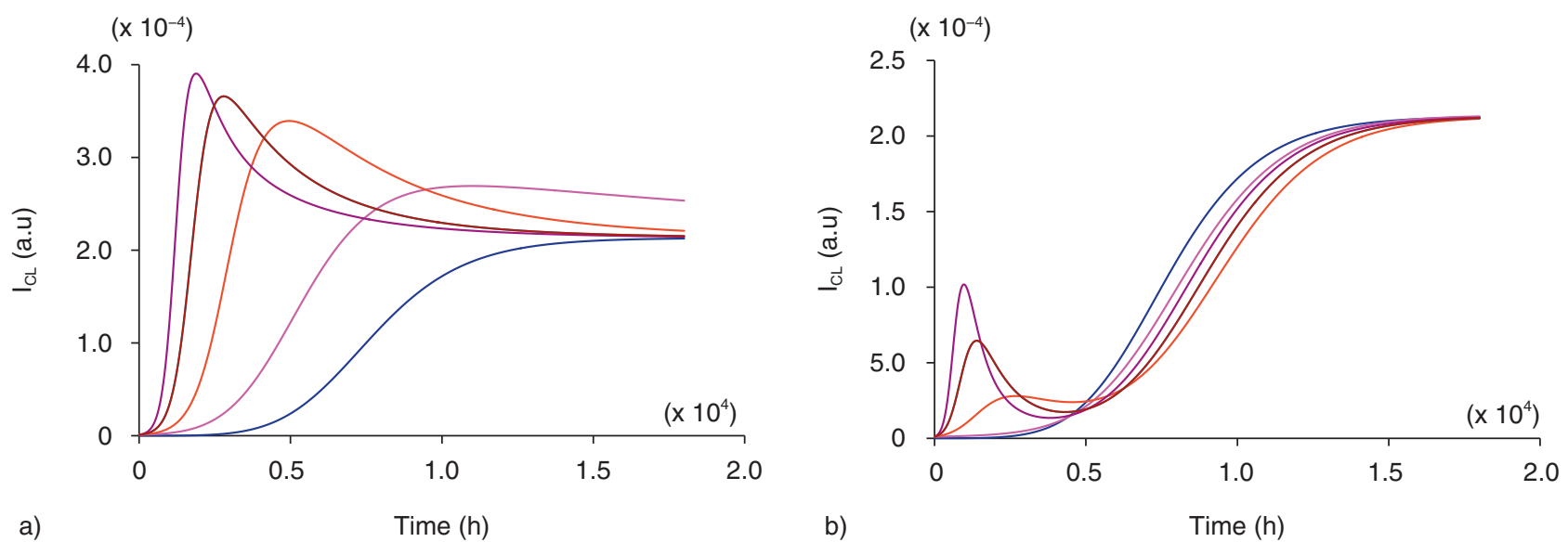

Figure 9

Simulation of CL runs with $k_{\mathrm{b} 11}=10^{-2} \mathrm{~L} \cdot \mathrm{mol}^{-1} \cdot \mathrm{s}^{-1}, k_{611}=10^{8} \mathrm{~L} \cdot \mathrm{mol}^{-1} \cdot \mathrm{s}^{-1},[\mathrm{POOH}]_{0}=10^{-2} \mathrm{~mol} \cdot \mathrm{L}^{-1}, k_{312}=k_{322}$ a) or $\left.k_{312}=0 \mathrm{~b}\right)$ for pure PE, PE + ME with $k_{311}=100,500,1000$ and $1500 \mathrm{~L} \cdot \mathrm{mol}^{-1} \cdot \mathrm{s}^{-1}$.

in PE at room temperature (see 'Oils Permeability in Polyethylene' section).

The following expression of chemiluminescence intensity can be derived:

$$
\begin{gathered}
I_{C L}=\Phi \times\left(k_{\mathrm{b} 11} \cdot[\mathrm{UFE}-\mathrm{OOH}]^{2}+k_{\mathrm{b} 12} \cdot[\mathrm{UFE}-\mathrm{OOH}] .\right. \\
\left.[\mathrm{PE}-\mathrm{OOH}]+k_{\mathrm{b} 22} \cdot[\mathrm{PE}-\mathrm{OOH}]^{2}\right)
\end{gathered}
$$

Simulations for CL curves are given in Figure 9 for several sets of rate constants differing only by $k_{311}$ and $k_{321}$ value. It is noteworthy that the best simulations were obtained using $k_{312}=0$ (instead of $k_{312}=k_{322}$ ). The shape of simulated CL curves is in reasonable agreement with experimental observations. 
It seems clear that whatever the $k_{311}$ value extrapolated at $150^{\circ} \mathrm{C}$, the $\mathrm{CL}$ curves can be simulated provided that the following inequality is verified:

$$
k_{311^{2}} / k_{611} \gg k_{322}^{2} / k_{622}
$$

i.e. that both compounds have a significantly different reactivity. The next step of the approach is to investigate if, in real conditions, the co-oxidation phenomenon is limited to the superficial layers of a thick PE tank (here represented by a thin film) or on the contrary if UFE methyl esters migrate into the PE bulk and promote its oxidation.

\subsection{Oils Permeability in Polyethylene}

Vegetable oils are more or less complex mixtures of fatty compounds. We focus here on their permeation properties (diffusion and solubility) in a general purpose grade of PE. It seemed to us interesting to compare rapeseed and soy methyl esters with their major components i.e. methyl oleate (C18:1) and methyl linoleate (C18:2). The gravimetric sorption curves display an equilibrium plateau at a weight gain c.a. $4-5 \%$ at room temperature (Fig. 10), which is almost independent of the ester nature and having the same value for the vegetable oils and for their major component confirming thus the pertinence of its choice as a model compound.

Since oils are supposed to penetrate only into the amorphous phase of the polymer, it seemed to us interesting to determine the oil equilibrium concentration $c$ in the amorphous phase from the equilibrium mass gain $w_{e q}$

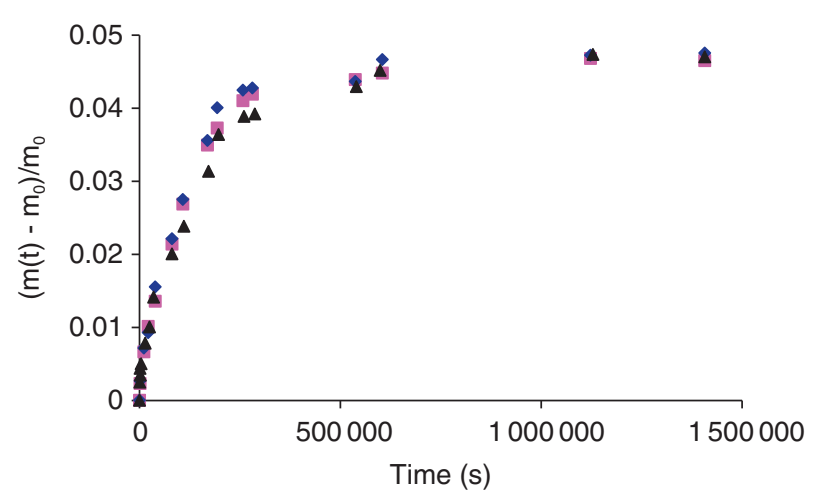

Figure 10

Mass uptake in polyethylene immersed in rapeseed methyl ester (measurement is done in triplicate). using the following relationship (assuming that densities of PE amorphous phase and methyl ester are equal):

$$
c=\frac{w_{e q} \cdot \rho_{a}^{P E}}{M_{e s t e r} \cdot\left(1-x_{C}\right) \cdot\left(1+w_{e q}\right)}
$$

where: $\rho_{a}{ }^{\mathrm{PE}}$ is the density of PE amorphous phase $\left(\rho_{a}{ }^{\mathrm{PE}}=850 \mathrm{~g} . \mathrm{L}^{-1}\right), \mathrm{M}_{\mathrm{ester}}$ is the molar mass of the methyl ester (taken equal to the average molar mass for the soy and rapeseed methyl esters), $x_{C}$ is the crystallinity ratio (here $x_{C} \sim 0.5$ ).

Equilibrium concentrations determined at 23, 45, 60 and $75^{\circ} \mathrm{C}$ are listed in Table 3. They call for the following comments:

- methyl linoleate is slightly but significantly less soluble than methyl oleate;

- vegetable methyl esters do not differ strongly from their major component;

- the solubility is an increasing function of temperature.

The relative mass uptake was plotted against square root of time in Figure 11 for rapeseed oil at the four temperatures under investigation. For the temperatures of $23^{\circ} \mathrm{C}, 45^{\circ} \mathrm{C}$ and $60^{\circ} \mathrm{C}$, the plots are linear $\left(R^{2} \geq 0.977\right)$ in the domain of low mass uptake indicating that diffusion obeys Fick's law. At the highest temperature $\left(75^{\circ} \mathrm{C}\right)$, the plots are clearly sigmoidal for all the samples under study. The diffusion coefficient $D$ was calculated from the slope of the straightline using:

$$
D=\frac{\pi L^{2}}{16} \cdot\left(\frac{d w / w_{e q}}{d \sqrt{t}}\right)^{2}
$$

Its values are listed in Table 4. For the temperature of $75^{\circ} \mathrm{C}$, we have taken the average slope but the corresponding $D$ values must be considered cautiously.

Data are well fitted by Arrhenius law.

In conclusion, the presented experimental results show that methyl esters derived from soy or rapeseed oil are relatively soluble in PE (roughly 5 to $10 \%$ in weight depending on temperature) together with a high diffusion rate $\left(10^{-13} \mathrm{~m}^{2} . \mathrm{s}^{-1}\right.$ corresponds to a time to reach equilibrium of c.a. 3 years for a $3 \mathrm{~mm}$ thick sample). In other words, fatty esters of the soy or rapeseed type can easily migrate towards PE bulk and promote its oxidative degradation (see above).

Let's us now turn to possible modeling for diffusivity prediction. The diffusivity can be considered as resulting from the balance between penetrant size $\left(V^{*}\right)$ and free volume $\left(V_{f}\right)$ permitting molecular jumps, as expressed by Cohen and Turnbull [32]:

$$
D=A \cdot \exp \left(-\gamma \frac{V^{*}}{V_{f}}\right)
$$



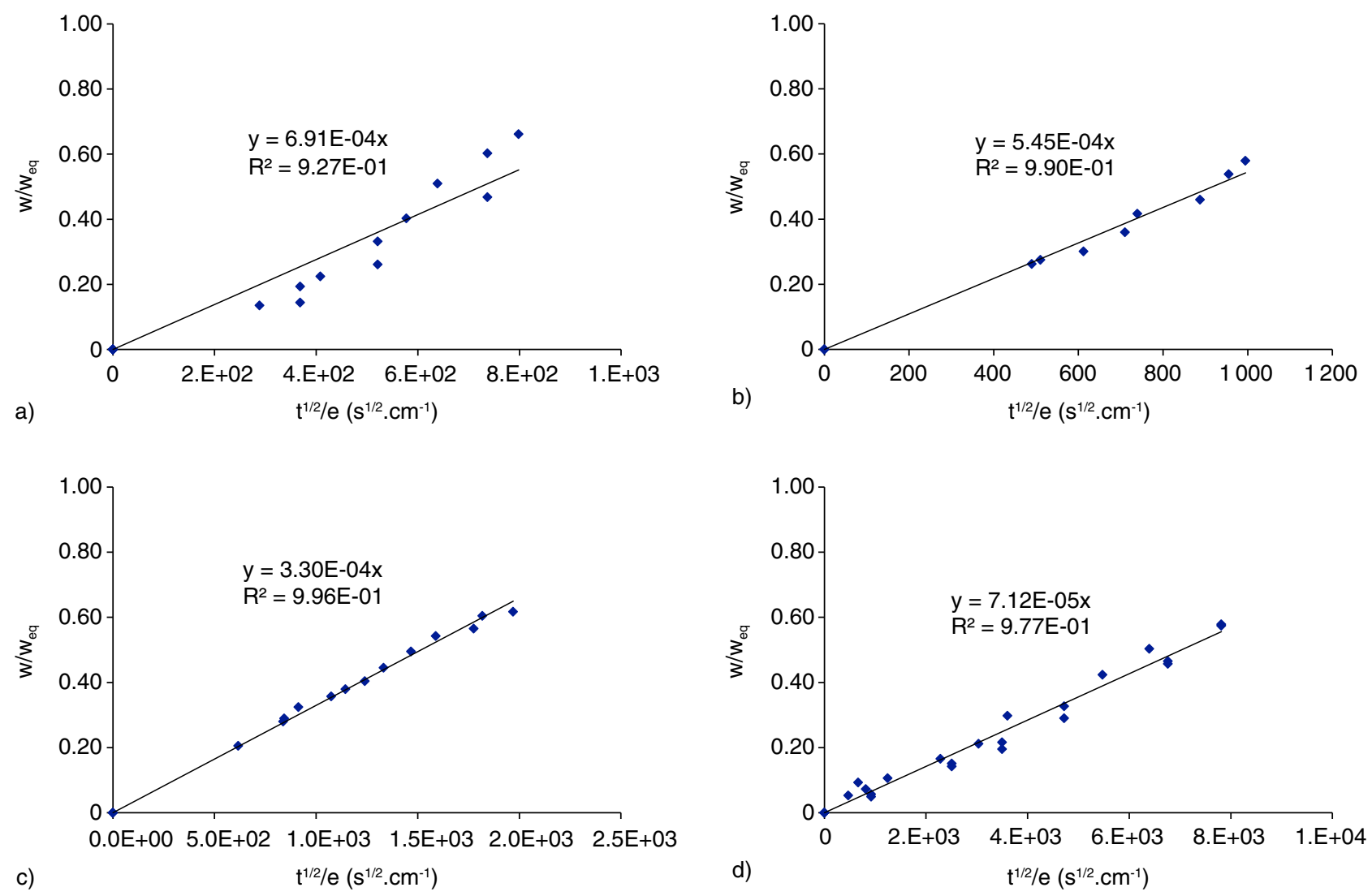

Figure 11

Relative mass uptake against square root of time for polyethylene films immersed in rapeseed methyl ester at $75^{\circ} \mathrm{C}$ a), $60^{\circ} \mathrm{C} \mathrm{b}$ ), $45^{\circ} \mathrm{C}$ c) and room temperature d).

TABLE 3

Equilibrium mass gain and corresponding concentration at the four temperatures under study

\begin{tabular}{|c|c|c|c|c|c|c|c|c|}
\hline \multirow[b]{2}{*}{$\mathrm{T}\left({ }^{\circ} \mathrm{C}\right)$} & \multicolumn{2}{|c|}{ Methyl oleate } & \multicolumn{2}{|c|}{ Methyl linoleate } & \multicolumn{2}{|c|}{ Rapeseed methyl ester } & \multicolumn{2}{|c|}{ Soy methyl ester } \\
\hline & $\mathrm{w}_{\mathrm{ep}}$ & $c\left(\right.$ mol. $\left.^{-1}\right)$ & $\mathrm{w}_{\mathrm{ep}}$ & $c\left(\mathrm{~mol} . \mathrm{L}^{-1}\right)$ & $\mathrm{w}_{\mathrm{ep}}$ & $c\left(\mathrm{~mol}^{-\mathrm{L}^{-1}}\right)$ & $\mathrm{w}_{\mathrm{ep}}$ & $c\left(\mathrm{~mol} \cdot \mathrm{L}^{-1}\right)$ \\
\hline 75 & 0.116 & 0.614 & 0.092 & 0.503 & 0.095 & 0.512 & 0.092 & 0.497 \\
\hline 60 & 0.070 & 0.389 & 0.064 & 0.358 & 0.071 & 0.393 & 0.069 & 0.382 \\
\hline 45 & 0.056 & 0.316 & 0.051 & 0.289 & 0.055 & 0.309 & 0.054 & 0.303 \\
\hline 23 & 0.047 & 0.265 & 0.042 & 0.238 & 0.047 & 0.267 & 0.047 & 0.268 \\
\hline
\end{tabular}

In which $\gamma$ is a parameter ranging between 0.5 and 1 . This theory has led to two sorts of models:

- non empirical models. The most sophisticated one was established by Vrentas and Duda [33]:

$$
\begin{gathered}
D_{1}=D_{01} \cdot \exp \left(-\frac{E}{R T}\right) \\
\times \exp \left(\begin{array}{c}
-\frac{\omega_{1} \hat{V}_{1}^{*}+\omega_{2} \xi \hat{V}_{2}^{*}}{\frac{K_{11} \omega_{1}\left(K_{21}-T_{g 1}+T\right)}{\gamma_{1}}+\frac{K_{12} \omega_{2}\left(K_{22}-T_{g 2}+T\right)}{\gamma_{2}}}
\end{array}\right)
\end{gathered}
$$

where $D_{1}$ is the penetrant self-diffusion coefficient, $E$ is the activation energy for a penetrant jump corresponding to the energy which is necessary for a molecule to overcome the attraction of neighboring molecules, $\omega_{1}$ and $\omega_{2}$ are the weight fractions of polymer and penetrant, $V_{i}^{*}$ is the specific volume necessary for a penetrant molecule or polymer segment jump, and $\xi$ is the ratio of penetrant and polymer jumping unit critical volumes.

This relationship is especially designed for cases where penetrant brings its own free volume so that diffusion is 
TABLE 4

Diffusion coefficients (in $\mathrm{m}^{2} \cdot \mathrm{s}^{-1}$ ) pre-exponential factor and activation energy for all the samples under study

\begin{tabular}{|c|c|c|c|c|c|c|}
\hline & $75^{\circ} \mathrm{C}$ & $60^{\circ} \mathrm{C}$ & $45^{\circ} \mathrm{C}$ & $23^{\circ} \mathrm{C}$ & $\begin{array}{c}\text { In } D_{0} \\
\left(D_{0} \text { in } \mathrm{m}^{2} \cdot \mathrm{s}^{-1}\right)\end{array}$ & $\begin{array}{c}\Delta H_{D} \\
\left(\mathrm{~kJ} \cdot \mathrm{mol}^{-1}\right)\end{array}$ \\
\hline Methyl oleate & $2.40 \times 10^{-11}$ & $8.21 \times 10^{-12}$ & $2.36 \times 10^{-12}$ & $1.39 \times 10^{-13}$ & 5.18 & 85.2 \\
\hline Methyl linoleate & $1.96 \times 10^{-11}$ & $5.02 \times 10^{-12}$ & $2.30 \times 10^{-12}$ & $1.13 \times 10^{-13}$ & 4.15 & 83.1 \\
\hline $\begin{array}{c}\text { Rapeseed methyl } \\
\text { ester }\end{array}$ & $1.82 \times 10^{-11}$ & $6.22 \times 10^{-12}$ & $2.12 \times 10^{-12}$ & $1.26 \times 10^{-13}$ & 3.69 & 81.8 \\
\hline Soy methyl ester & $2.56 \times 10^{-11}$ & $6.48 \times 10^{-12}$ & $2.10 \times 10^{-12}$ & $1.25 \times 10^{-13}$ & 5.63 & 86.7 \\
\hline
\end{tabular}

TABLE 5

Model parameters from Begley et al. [35]

\begin{tabular}{c|c|c|c}
\hline Polymer & $A_{P}$ & $\tau$ & Temperature \\
\hline LDPE & 11.5 & 0 & $<90^{\circ} \mathrm{C}$ \\
\hline HDPE & 14.5 & 1577 & $<100^{\circ} \mathrm{C}$ \\
\hline PP homopolymer & 13.1 & 1577 & $<120^{\circ} \mathrm{C}$ \\
\hline PP rubber & 11.5 & 0 & $<100^{\circ} \mathrm{C}$ \\
\hline PS & 0.0 & 0 & $<70^{\circ} \mathrm{C}$ \\
\hline HIPS & 1.0 & 0 & $<70^{\circ} \mathrm{C}$ \\
\hline PET & 6.0 & 1577 & $<175^{\circ} \mathrm{C}$ \\
\hline PEN & 5.0 & 1577 & $<175^{\circ} \mathrm{C}$ \\
\hline PA66 & 2.0 & 0 & $<100^{\circ} \mathrm{C}$ \\
\hline
\end{tabular}

auto-facilitated. However, its implementation required the determination of several coefficients a priori unknown.

Molecular (empirical) models also express diffusion coefficient in function of penetrant size (the most often its molar mass), temperature, and polymer structure dependant parameters. They were developed for predicting migration of chemicals from food packaging. They work especially well for linear molecules [34]. An example of these models is the following one:

$D=10^{4} \cdot \exp \left(A_{p}-0.1351 . M_{r}^{2 / 3}+0.003 \cdot M_{r}-\frac{10454+\tau}{T}\right)$

in which: $D$ is expressed in $\mathrm{cm}^{2} \cdot \mathrm{s}^{-1}, M_{r}$ being the molar mass of the penetrant expressed in g.mol ${ }^{-1}, A_{P}$ and $\tau$ depend on polymer matrix nature.

The parameter values determined by Begley et al. [35] for some polymers are listed in Table 5 .

It is easy to verify that despite its simplicity:

- this model permits a fair prediction of diffusivity values,

- the prediction of temperature effect is excellent.
This model can be thus applied in the case under study, to predict the diffusivity values of biofuels in PE.

\section{CONCLUSIONS}

This paper provides an overview perspective how lifetime of polyethylene in contact of ethanol based or biofuel based fuels can be predicted. Indeed, embrittlement time of polyethylene parts is governed by several processes such as physical interactions (stress cracking, additive extraction) or chemical interactions (polymer oxidation promoted by fuel oxidation). Here, Arrhenius law cannot be applied to the whole ageing process owing to the complexity of mechanisms involving several processes of diffusion (oil, oxygen and stabilizers with distinct timescales) and chemical processes (oxidation). The classical method consisting of using Arrhenius law to predict lifetime from experimental results obtained at high temperature (typically $T \geq 100^{\circ} \mathrm{C}$ ) is thus questionable here.

Thanks to numerical methods, a non-empirical kinetic model can be derived from a realistic mechanistic scheme 
to simulate property changes, for instance carbonyl growth. The main advantage of this analytical approach is that stabilizers which are frequently present in commercial polyethylene can be included into the simulation since kinetic parameters are already known for the pure polymer. Some simulation results have been reported for stabilized polyethylene, it has been shown how they may guide extrapolations towards lower temperatures. Furthermore, this kinetic approach can include physical phenomena occurring during the degradation process as stabilizers physical loss. It has been found that the stabilizer depletion rate is reduced when ethanol content increases and obeys Arrhenius law.

A specific attention has been paid to chemical interaction between oil and PE. It has been shown that unsaturated fatty esters can penetrate into $\mathrm{PE}$ and thus promotes PE oxidation. A kinetic model involving all these processes has been proposed. The predictive value of this approach has been partially checked from chemiluminescence experiments.

\section{REFERENCES}

1 Djouani F., Richaud E., Fayolle F., Verdu J. (2011) Modelling of thermal oxidation of phosphite stabilized polyethylene, Polym. Degrad. Stab. 96, 7, 1349-1360.

2 Djouani F., Patel V., Richaud E., Fayolle B., Verdu J. (2012) Antioxidants loss kinetics in polyethylene exposed to model ethanol based biofuels, Fuel 93, 502-509.

3 Richaud E., Flaconnèche B., Verdu J. (2012) Biodiesel permeability in polyethylene, Polymer Testing 31, 8, 10701076.

4 Richaud E., Fayolle B., Verdu J., Rychlý J. (2013) Co-oxidation kinetic model for the thermal oxidation of polyethylene-unsaturated substrate systems, Polym. Degrad. Stab. 98, 5, 1081-1088.

5 Khelidj N., Colin X., Audouin L., Verdu J., Monchy-Leroy C., Prunier V. (2006) Oxidation of polyethylene under irradiation at low temperature and low dose rate. Part II. Low temperature thermal oxidation, Polym. Degrad. Stab. 91, 7, 1598-1605.

6 Fayolle B., Richaud E., Colin X., Verdu J. (2008) Review: Degradation induced embrittlement in semi-crystalline polymers having their amorphous phase in rubbery state, J. Mater. Sci. 43, 6999-7012.

7 Kennedy M.A., Peacock A.J., Mandelkern L. (1994) Tensile properties of crystalline polymers: Linear polyethylene, Macromolecules 27, 19, 5297-5310.

8 Fayolle B., Verdu J., Piccoz D., Dahoun A., Hiver J.M., G'Sell C. (2009) Thermooxidative ageing of polyoxymethylene Part 2: Embrittlement mechanisms, J. Appl. Polym. Sci. 111,1, 469-475.

9 Fayolle B., Audouin L., Verdu J. (2004) A critical molar mass separating the ductile and brittle regimes as revealed by thermal oxidation in polypropylene, Polymer 45,12, 4323-4330.
10 McCall D.W., Douglass D.C., Blyler Jr L.L., Johnson G. E., Jelinski L.W., Bair H.E. (1984) Solubility and diffusion of water in low-density polyethylene, Macromolecules 17, 9, 1644-1649.

11 Russell G.A., Williamson Jr R.C. (1964) Directive effects in aliphatic substitutions. XXV. Reactivity of aralkanes, aralkenes, and benzylic ethers toward peroxy radicals, $J$. Am. Chem. Soc. 86, 12, 2364-2367.

12 Rincon-Rubio L.M., Fayolle B., Audouin L., Verdu J. (2001) A general solution of the Closed-loop kinetic scheme for the thermal oxidation of polypropylene, Polym. Degrad. Stab. 74, 1, 177-188.

13 Colin X., Richaud E., Verdu J., Monchy-Leroy C. (2010) Kinetic modelling of radiochemical ageing of ethylenepropylene copolymers, Radiat. Phys. Chem 79, 3, 365-370.

14 So P.K., Broutman L.J. (1986) The fracture behavior of surface embrittled polymers, Polym. Eng. Sci. 26, 17, 1173-1179.

15 Schoolenberg G.E. (1988) A fracture mechanics approach to the effects of UV-degradation on polypropylene, $J$. Mater. Sci. 23, 5, 1580-1590.

16 Colin X., Audouin L., Verdu J., Rozental-Evesque M., Rabaud B., Martin F., Bourgine F. (2009) Aging of polyethylene pipes transporting drinking water disinfected by chlorine dioxide. Part II - Lifetime prediction, Polym. Eng. Sci. 49, 8, 1642-1652.

17 Verdu J. (2012) Oxidative Ageing of Polymers, John Wiley \& Sons, Inc., Hoboken, NJ, USA.

18 Chirinos-Padrón A.J., Hernández P.H., Allen N.S., Vasilion C., Marshall G.P., de Poortere M. (1987) Synergism of antioxidants in high density polyethylene, Polym. Degrad. Stab. 19, 2, 177-189.

19 Al-Malaika S., Goodwin C., Issenhuth S., Burdick D. (1999) The antioxidant role of $\alpha$-tocopherol in polymers II. Melt stabilising effect in polypropylene, Polym. Degrad. Stab. 64, 1, 145-156.

20 Verdu J., Rychly J., Audouin L. (2003) Synergism between polymer antioxidants-kinetic modelling, Polym. Degrad. Stab. 79, 3, 503-509.

21 Zweifel H. (1996) Effect of stabilization of polypropylene during processing and its influence on long term behavior under thermal stress, Polymer Durability. Advances in Chemistry Series 249, Clough R.L., Billingham N., Gillen K.T. (eds), American Chemical Society, Washington

22 Fearon P.K., Phease T.L., Billingham N.C., Bigger S.W. (2002) A new approach to quantitatively assessing the effects of polymer additives, polymer 43, 17, 4611-4618.

23 Schwetlick K., Pionteck J., Winkler A., Hähner U., Kroschwitz H., Habicher W.D. (1991) Organophosphorus antioxidants: Part X - Mechanism of antioxidant action of aryl phosphites and phosphonites at higher temperatures, Polym. Degrad. Stab. 31, 2, 219-228.

24 Peinado C., Corrales T., García-Casas M.J., Catalina F., Ruiz Santa Quiteria V., Parellada M.D. (2006) Chemiluminescence from poly(styrene-b-ethylene-co-butylene-b-styrene) (SEBS) block copolymers, Polym. Degrad. Stab. 91, 4, 862-874.

25 Mallégol J., Carlsson D.J., Deschênes L. (2001) A comparison of phenolic antioxidant performance in HDPE at $32-$ $80^{\circ} \mathrm{C}$, Polym. Degrad. Stab. 73, 2, 259-267. 
26 Vitrac O., Mougharbel A., Feigenbaum A. (2007) Interfacial mass transport properties which control the migration of packaging constituents into foodstuffs, J. Food Eng. 79, 3, 1048-1064.

27 Demirbas A. (2005) Biodiesel production from vegetable oils via catalytic and non-catalytic supercritical methanol transesterification methods, Progr. Energ. Combust. Sci. 31, 5-6, 466-487.

28 Broska R., Rychlý J. (2001) Double stage oxidation of polyethylene as measured by chemiluminescence, Polym. Degrad. Stab. 72, 2, 271-278.

29 Decker C., Mayo F.R., Richardson H. (1973) Aging and degradation of polyolefins - 3. Polyethylene and ethylenepropylene copolymers, J. Polym. Sci. Part A-1: Polym. Chem. 11, 11, 2879-2898.

30 Korcek S., Chenier J.H.B., Howard J.A., Ingold K.U. (1972) Absolute Rate Constants for Hydrocarbon Autoxidation. XXI. Activation Energies for Propagation and the Correlation of Propagation Rate Constants with CarbonHydrogen Bond Strengths, Can. J. Chem. 50, 2285-2297.

31 Denisov E.T., Afanas'ev I.B. (2005) Oxidation and Antioxidants in Organic Chemistry and Biology, CBC Taylor \& Francis Group, Boca Raton, London, New York, Singapore.
32 Cohen M.H., Turnbull D. (1959) Molecular transport in liquids and glasses, J. Chem Phys. 31, 1164-1169.

33 Vrentas J.S., Duda J.L. (1977) Diffusion in polymer - Solvent systems -2 . A predictive theory for the dependence of diffusion coefficients on temperature, concentration and molecular weight, J. Polym. Sci. Polym. Phys. Ed 15, 3, 417-439.

34 Brandsch B., Mercea P., Piringer O. (2000) Modeling of Additive Diffusion Coefficients in Polyolefins, in Food Packaging Testing Methods and Applications. ACS Symposium Series 753, Risch S.J. (ed.). Washington DC.

35 Begley T., Castle L., Feigenbaum A., Franz R., Hinrichs K., Lickly T., Mercea P., Milana M., O’Brien A., Rebre S., Rijk R., Piringer O. (2005) Evaluation of migration models that might be used in support of regulations for food-contact plastics, Food Addit. Contam. 22, 1, 73-90.

Manuscript accepted in May 2013 Published online in November 2013

Cite this article as: E. Richaud, F. Djouani, B. Fayolle, J. Verdu and B. Flaconneche (2015). New Insights in Polymer-Biofuels Interaction, Oil Gas Sci. Technol 70, 2, 317-333. 